\title{
Research on Supersonic Inlet Bleed
}

David O. Davis, Manan A. Vyas, and John W. Slater

Glenn Research Center, Cleveland, Ohio 


\section{NASA STI Program . . . in Profile}

Since its founding, NASA has been dedicated to the advancement of aeronautics and space science. The NASA Scientific and Technical Information (STI) program plays a key part in helping NASA maintain this important role.

The NASA STI Program operates under the auspices of the Agency Chief Information Officer. It collects, organizes, provides for archiving, and disseminates NASA's STI. The NASA STI program provides access to the NASA Aeronautics and Space Database and its public interface, the NASA Technical Reports Server, thus providing one of the largest collections of aeronautical and space science STI in the world. Results are published in both non-NASA channels and by NASA in the NASA STI Report Series, which includes the following report types:

- TECHNICAL PUBLICATION. Reports of completed research or a major significant phase of research that present the results of NASA programs and include extensive data or theoretical analysis. Includes compilations of significant scientific and technical data and information deemed to be of continuing reference value. NASA counterpart of peer-reviewed formal professional papers but has less stringent limitations on manuscript length and extent of graphic presentations.

- TECHNICAL MEMORANDUM. Scientific and technical findings that are preliminary or of specialized interest, e.g., quick release reports, working papers, and bibliographies that contain minimal annotation. Does not contain extensive analysis.

- CONTRACTOR REPORT. Scientific and technical findings by NASA-sponsored contractors and grantees.
- CONFERENCE PUBLICATION. Collected papers from scientific and technical conferences, symposia, seminars, or other meetings sponsored or cosponsored by NASA.

- SPECIAL PUBLICATION. Scientific, technical, or historical information from NASA programs, projects, and missions, often concerned with subjects having substantial public interest.

- TECHNICAL TRANSLATION. Englishlanguage translations of foreign scientific and technical material pertinent to NASA's mission.

Specialized services also include creating custom thesauri, building customized databases, organizing and publishing research results.

For more information about the NASA STI program, see the following:

- Access the NASA STI program home page at http://www.sti.nasa.gov

- E-mail your question to help@sti.nasa.gov

- Fax your question to the NASA STI Information Desk at 443-757-5803

- Phone the NASA STI Information Desk at 443-757-5802

- Write to: STI Information Desk NASA Center for AeroSpace Information 7115 Standard Drive Hanover, MD 21076-1320 
NASA/TM-2012-217620

AIAA-2012-0272

\section{Research on Supersonic Inlet Bleed}

David O. Davis, Manan A. Vyas, and John W. Slater

Glenn Research Center, Cleveland, Ohio

Prepared for the

50th Aerospace Sciences Meeting

sponsored by the American Institute of Aeronautics and Astronautics

Nashville, Tennessee, January 9-12, 2012

National Aeronautics and

Space Administration

Glenn Research Center

Cleveland, Ohio 44135 


\section{Acknowledgments}

The authors would like to thank R.C. Clark, B.T. Seifert, R.G. Senyitko, J.M. Lucero, D.W. Hammett, C. Horn, and S.M. Velez of NASA Glenn Research Center for matters concerning the wind tunnel and gas bench operation. Funding from the Supersonics Project of the NASA Fundamental Aeronautics Program is gratefully acknowledged.

This report contains preliminary findings, subject to revision as analysis proceeds.

Trade names and trademarks are used in this report for identification only. Their usage does not constitute an official endorsement, either expressed or implied, by the National Aeronautics and Space Administration.

This work was sponsored by the Fundamental Aeronautics Program at the NASA Glenn Research Center.

Level of Review: This material has been technically reviewed by technical management.

Available from

NASA Center for Aerospace Information 7115 Standard Drive

Hanover, MD 21076-1320
National Technical Information Service 5301 Shawnee Road Alexandria, VA 22312 


\title{
Research on Supersonic Inlet Bleed
}

\author{
David O. Davis, Manan A. Vyas, and John W. Slater \\ National Aeronautics and Space Administration \\ Glenn Research Center \\ Cleveland, Ohio 44135
}

\begin{abstract}
Phase I data results of the Fundamental Inlet Bleed Experiments project at NASA Glenn Research Center (GRC) are presented which include flow coefficient results for two single-hole boundary-layer bleed configurations. The bleed configurations tested are round holes at inclination angles of $90^{\circ}$ and $20^{\circ}$ both having length-to-diameter ratios of 2.0. Results were obtained at freestream Mach numbers of 1.33, $1.62,1.98,2.46$, and 2.92 and unit Reynolds numbers of $0.984,1.89$, and $2.46 \times 10^{7} / \mathrm{m}$. Approach boundary-layer data are presented for each flow condition and the flow coefficient results are compared to existing multi-hole data obtained under similar conditions. For the $90^{\circ}$ hole, the single and multi-hole distributions agree fairly well with the exception that under supercritical operation, the multi-hole data chokes at higher flow coefficient levels. This behavior is also observed for the $20^{\circ}$ hole but to a lesser extent. The $20^{\circ}$ hole also shows a markedly different characteristic at subcritical operation. Also presented are preliminary results of a Computational Fluid Dynamics (CFD) analysis of both configurations at the Mach 1.33 and a unit Reynolds number of $2.46 \times 10^{7} / \mathrm{m}$. Comparison of the results shows the agreement to be very good.
\end{abstract}

\section{Nomenclature}

$\begin{array}{ll}A_{b} & \text { Bleed hole area } \\ A_{\text {min }} & \text { Minimum area of bleed orifice } \\ D & \text { Bleed hole diameter } \\ g_{\mathrm{c}} & \text { Proportionality constant } \\ H_{\text {inc }} & \text { Incompressible shape factor } \\ L & \text { Bleed hole length } \\ \mathrm{M} & \text { Mach number or molecular weight } \\ \mathrm{M}_{b l k} & \text { Nominal Mach number of wind tunnel fixed geometry convergent-divergent nozzle } \\ \mathrm{M}_{\text {noz }} & \text { Actual Mach number of wind tunnel fixed geometry convergent-divergent nozzle } \\ \mathrm{ppm} & \text { parts per million (volume fraction) } \\ P & \text { Static pressure } \\ P_{t} & \text { Total pressure } \\ Q & \text { Sonic flow coefficient } \\ R & \text { Gas constant } \\ \mathrm{Re}_{\mathrm{Re}} & \text { Unit Reynolds number } \\ \mathrm{Re}^{\prime} & \text { Scaled Reynolds number }(\text { Re } \times 1.0 \mathrm{E}-07 \mathrm{~m}) \\ \mathrm{sccm} & \text { standard cubic centimeters per minute } \\ \text { slm } & \text { standard liters per minute } \\ t & \text { Bleed plate thickness } \\ T & \text { Static temperature } \\ T_{t} & \text { Total temperature }\end{array}$




$\begin{array}{ll}U & \text { Streamwise velocity component } \\ w & \text { Mass-flow rate } \\ x, y, z & \text { Cartesian coordinate system, } x \text { relative to nozzle exit plane } \\ x_{\text {win }} & \text { Coordinate relative to Test Section } \# 1 \text { top window leading edge }\end{array}$

Greek Symbols:

$\begin{array}{ll}\alpha & \text { Bleed hole inclination angle } \\ \delta & \text { Boundary-layer thickness } \\ \delta_{1} & \text { Boundary-layer displacement thickness } \\ \gamma & \text { Ratio of specific heats } \\ \nu & \text { Volume fraction of gas }\end{array}$

Subscripts:

$0 \quad$ Pertaining to the wind tunnel plenum chamber condition

air Pertaining to air gas

$e \quad$ Pertaining to boundary-layer edge condition

i Pertaining to ideal conditions

met Pertaining to methane gas

plen Pertaining to the bleed plenum condition

wall Pertaining to wall condition

Superscripts:

* $\quad$ Pertaining to choked conditions

\section{Introduction}

An ongoing effort at NASA Glenn Research Center (GRC) has been the development of improved bleed models for Computational Fluid Dynamics (CFD) codes used to aid in the design of supersonic inlets. Accurate prediction of the bleed orifice flow coefficient which relates bleed plenum pressure to mass flow removed is important to predicting inlet performance as well as estimating bleed drag. Much of the flow coefficient data at conditions of interest to inlet designers is based on bleed plates with multiple rows of holes. The flow coefficient for these plates is typically presented as a function of bleed plenum pressure normalized by the freestream total pressure. Further, the flow coefficient is typically referenced to the ideal sonic mass flow which is also based on the freestream total conditions. The use of freestream conditions is suitable for undisturbed core flow, but bleed regions are necessarily placed in the vicinity of shock waves where the freestream condition may not be relevant to the local conditions at the orifice entrance. Thus, a model that relates the flow coefficient to local conditions is desirable. Slater (Ref. 1) recently presented the results of such a model for $90^{\circ}$ bleed holes based on the experimental data of Willis et al. (Ref. 2). The use of multi-hole data to develop flow coefficient models that are applied to individual holes based on local conditions may be misleading due the interaction of adjacent holes. Davis (Ref. 3) has shown that the overall flow coefficient of two adjacent normal holes at Mach 2.46 can vary be by as much as 6 percent at choked conditions depending on the orientation of the holes to one another. The conclusion to that study was that it was anticipated that multi-hole configurations would tend to exhibit higher flow coefficient levels than their single-hole counterpart. Reported herein are the results of singlehole bleed flow coefficient experiments and their comparison to the multi-hole data of Willis et al. 


\section{Fundamental Inlet Bleed Experiments (FIBE)}

The Fundamental Inlet Bleed Experiments (FIBE) project is a research effort at NASA GRC to provide a comprehensive experimental database and a better understanding of how bleed systems can be improved through better modeling, alternate bleed configurations, and bleed placement within supersonic and hypersonic inlets. A number of events lead to the initiation of the project and are summarized as follows:

- June 1992 - Inlet/Nozzle Technology for the 1990s Workshop was held at the Ohio Aerospace Institute (OAI).

- An outcome of that workshop was the need for a Bleed Specific Workshop

- September 1993 - Inlet Bleed Technology Workshop was held at OAI.

- Bleed research needs were identified.

- 1994 to 1997 -NASA LeRC had an active bleed research program primarily in the $1 \times 1 \mathrm{ft}$ Supersonic Wind Tunnel (SWT) but also the $15 \times 15 \mathrm{~cm}$ SWT.

- A summary of this research was presented by Davis (Ref. 4) at the 1st Annual Shock

Wave/Boundary Layer Interaction (SBLI) Workshop (2008).

- 2007-The Inlet and Nozzle Branch at NASA GRC made a decision to re-establish some of the bleed research capability in the $15 \times 15 \mathrm{~cm}$ SWT.

- 2011—Fundamental Inlet Bleed Experiments project initiated.

The $15 \times 15 \mathrm{~cm}$ SWT was chosen for initial research due to its flexible test section and lower operating costs than some of GRC's larger tunnels. Due to limited bleed vacuum capacity of the $15 \times 15 \mathrm{~cm}$ SWT, the research conducted in the 1990s was limited to single or small array orifice studies. In addition to detailed flow field and surface measurements in the vicinity of a bleed orifice (Refs. 5 to 8) flow coefficient data for various hole configurations were also obtained (Ref. 3). Since the initial testing under the FIBE project is focused on the flow coefficient behavior of single-hole configurations, the $15 \times 15 \mathrm{~cm}$ SWT is ideally suited.

\section{FIBE Phase Planning}

The FIBE project is planned to be conducted in three phases. Phase I will include facility checkout and acquisition of flow coefficient data using pre-existing test hardware. The checkouts will include verification of the recently upgraded trace gas system for mass-flow measurement (described below) as well as establishing the operating envelope of the current bleed system. This will include evaluation of the sample pump capacity, system response time and bleed vacuum capacity (mechanical Stokes pump and altitude exhaust). Also during Phase I, approach boundary-layer profiles will be established for each Mach number at several Reynolds numbers. Then, single-hole flow coefficient data will be obtained using existing $90^{\circ}$ and $20^{\circ}$ bleed holes for comparison with existing multi-hole data.

Phase II will be an extension of Phase I and will investigate single-hole flow coefficient behavior including the effects of:

- Hole inclination angle $(\alpha)$

- Hole length to diameter ratio $(L / D)$

- Hole diameter to boundary-layer displacement thickness ratio $\left(D / \delta_{1}\right)$

- Hole shape and/or entrance contouring

- Detailed flow field measurements

These results will be used to validate CFD results as well as to develop improved bleed models. 
Phase III will study multi-hole bleed regions with and without shock waves present. These results will be used to validate CFD results under inlet-like flow conditions. These studies will require upgrades to the existing bleed system of the $15 \times 15 \mathrm{~cm}$ SWT which will include larger bleed lines and increased vacuum capacity through the installation of an ejector system.

\section{Facilities}

Phase I and II testing will be performed in the NASA GRC $15 \times 15 \mathrm{~cm}$ Supersonic Wind Tunnel (SWT), which is described below. Phase III testing will be performed in either the $15 \times 15 \mathrm{~cm}$ SWT or the NASA GRC $1 \times 1 \mathrm{ft}$ SWT, depending on the scale required to meet the test objectives. The $1 \times 1 \mathrm{ft}$ SWT operates in a very similar manner to the $15 \times 15 \mathrm{~cm} \mathrm{SWT}$, but also has a 450 psig ejector system as a bleed vacuum source. In addition to unit bleed studies, the $1 \times 1 \mathrm{ft}$ SWT is also large enough for small inlet models that may incorporate bleed. The potential also exists to test bleed configurations in a large scale $40 / 60$ axisymmetric mixed compression inlet in the $10 \times 10 \mathrm{ft} \mathrm{SWT}$. This test would be combined with an already proposed test to evaluate micro-vortex generators.

\section{FIBE Phase I Test Program}

FIBE Phase I testing began on April 29, 2011 and concluded on September 13, 2011. Based on the data obtained, improvements to the system were identified and a number of changes were made. Some of these improvements included complete re-alignment of the wind tunnel components, probe z-traverse mechanism alignment and sealing improvements, upgrade of the sample pumps to higher capacity, as well as some operational procedures to reduce data acquisition time.

\section{Test Hardware}

A schematic of a single bleed hole with reference parameters is shown in Figure 1. In this figure, we distinguish between a thick plate and a thin bleed plate. A thick bleed plate, which is illustrated in Figure 1(a), is defined as one in which the minimum flow area is equal to the area normal to the hole axis. If the diameter of the hole is maintained constant and the thickness of the plate is decreased, a point is reached where further reduction in the thickness results in a condition where the minimum flow area is not normal to the hole axis. This condition is defined as a thin bleed plate and is illustrated in Figure 1(b). The normalized thickness which separates a thick from a thin plate occurs when:

$$
\frac{t}{D}=\cos \alpha
$$

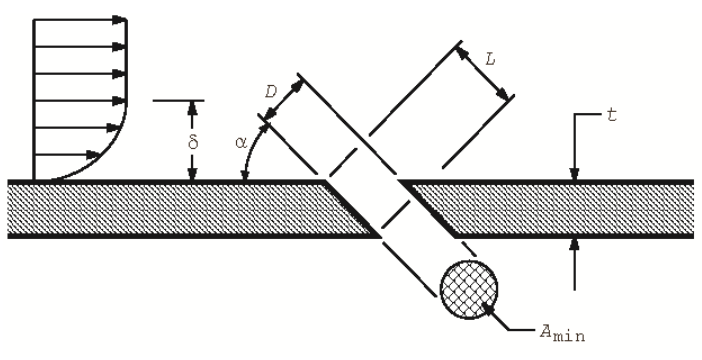

a) "Thick" bleed plate

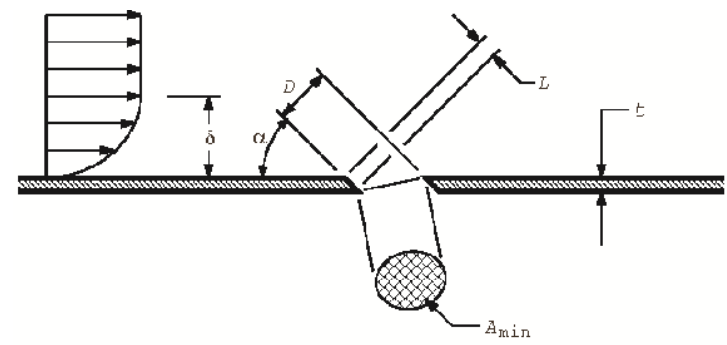

b) "Thin" bleed plate

Figure 1.-Schematic of bleed holes with reference parameters. 
Thus, for a round bleed hole in a "thick" plate, the minimum flow area is circular with the area defined as:

$$
A_{\text {min, thick }}=A_{b}=\frac{\pi}{4} D^{2} \quad\left(\frac{t}{D} \geq \cos \alpha\right)
$$

and, for a "thin" plate the minimum flow area is elliptical with the area defined as:

$$
A_{\text {min,thin }}=A_{b} \sqrt{\left(\frac{t}{D}\right)^{2}+\left(\frac{1-\frac{t}{D} \cdot \cos \alpha}{\sin \alpha}\right)^{2}} \quad\left(\frac{t}{D}<\cos \alpha\right)
$$

Note that as $\alpha \rightarrow 90^{\circ}$ for a thin plate, $t / D \rightarrow 0$ and, as expected, any plate thickness is considered thick for normal holes. A plot of the normalized minimum flow area of a bleed hole as a function of normalized bleed plate thickness for various hole inclination angles is shown in Figure 2. Finally, the normalized length of the bleed hole is given by:

$$
\frac{L}{D}=\frac{t}{D} \frac{1}{\sin \alpha}
$$

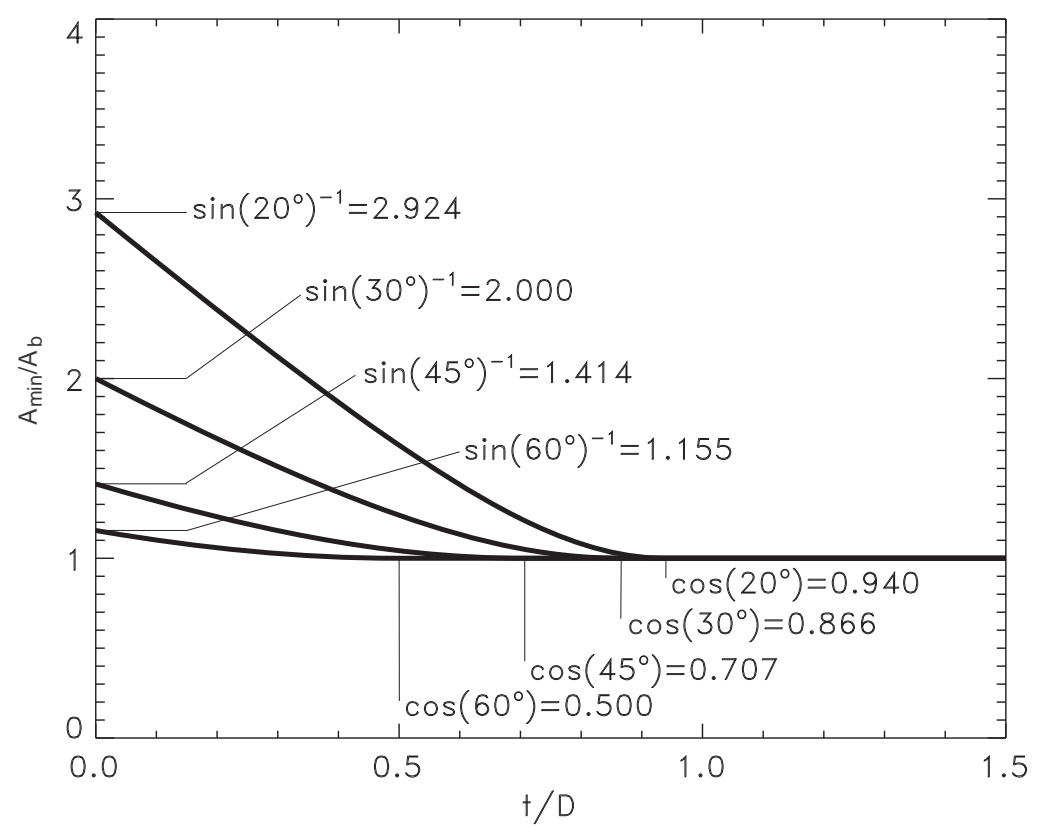

Figure 2.-Area ratio versus normalized plate thickness. 

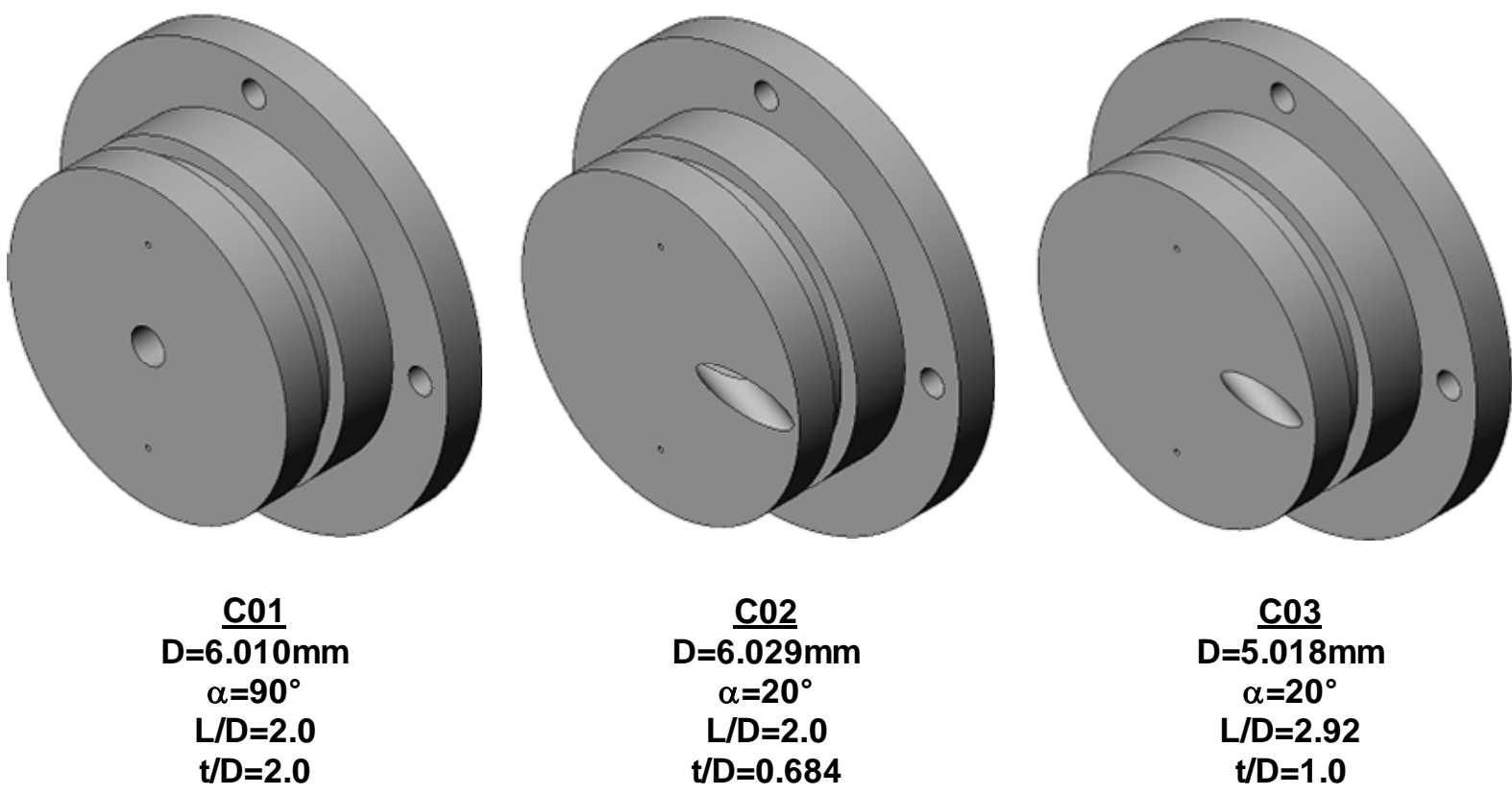

Figure 3.-Phase I test article configurations.

For the Phase I testing, three pre-existing single-hole test articles were used to check out the bleed system operation. The test articles consist of one $90^{\circ}$ (normal) hole, and two $20^{\circ}$ hole configurations as shown in Figure 3. The bleed holes are machined into interchangeable $50.8 \mathrm{~mm}$ (2.0 in.) diameter round plugs that are installed into the upper window of the wind tunnel test section. The $90^{\circ}(\mathrm{C} 01)$ and one of the $20^{\circ}(\mathrm{C} 02)$ bleed holes have a nominal hole diameter of $6.0 \mathrm{~mm}$ and a length-to-diameter $(L / D)$ ratio of 2.0. The other $20^{\circ}$ bleed hole (C03) has a nominal diameter of $5 \mathrm{~mm}$ and an $L / D$ ratio of 2.92 . Note that configuration C02, satisfying Equation (3), is considered to be a "thin" bleed plate and for its $t / D=0.684$, the minimum flow area is 24.8 percent above the bleed hole area. It should also be noted that at shallow bleed hole inclination angles, the actual minimum area may be significantly higher due to breaking or radiusing of the sharp hole edge.

\section{Test Facility}

The FIBE Phase I testing was conducted in the $15 \times 15 \mathrm{~cm} \mathrm{SWT}$, which is a continuous flow facility with Mach number set by interchangeable fixed-geometry convergent-divergent (C-D) nozzle blocks. The current Mach number capability is $\mathrm{M}=0.3$ to 0.8 for subsonic operation and $\mathrm{M}=1.4,1.7,2.0,2.5$, and 3.0 for supersonic operation. The total temperature is nominally ambient. The wind tunnel is supplied with lab-wide 40 psig combustion air and exhausts to lab-wide Altitude Exhaust which is maintained below $13.8 \mathrm{kPa}(2.0 \mathrm{psia})$. A sketch of the $15 \times 15 \mathrm{~cm}$ SWT is shown in Figure 4 .

Test Section \#1 is configured to accept the test articles as shown in Figure 3. The top window insert of Test Section \#1 is machined to accept the test articles shown in Figure 5. A plate is attached on the top of the window insert to form the bleed plenum. The bleed flow exhausts through a male barb fitting that screws into the plenum plate. The side window inserts have schlieren glass installed for flow visualization and the bottom window insert has three rows of axial pressure taps. 


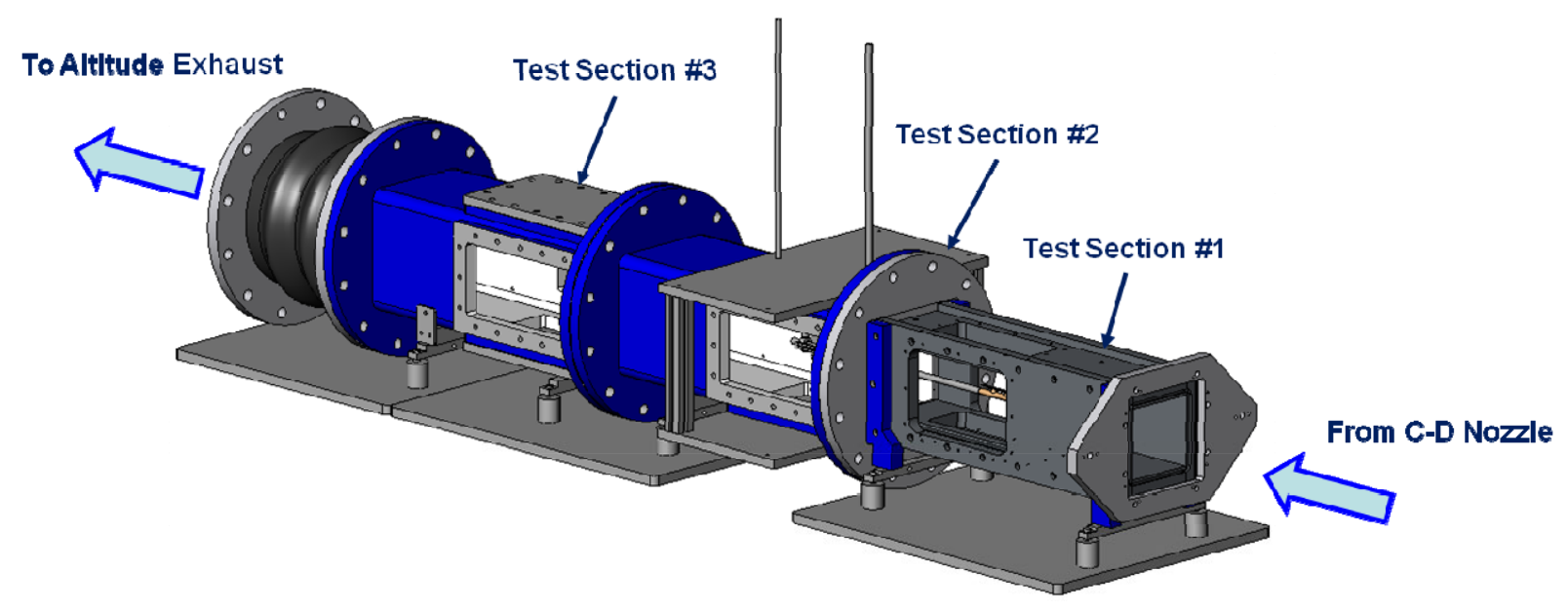

Figure 4.-15×15 cm Supersonic Wind Tunnel.

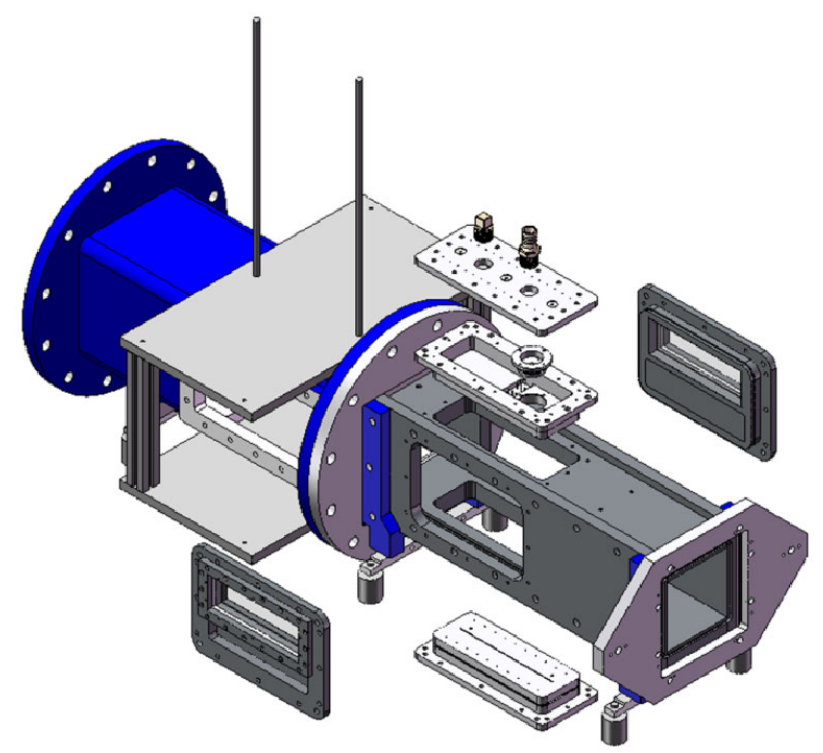

Figure 5.-Bleed setup in test section \#1.

\section{Instrumentation}

The instrumentation consists primarily of pressure measurements to monitor the flow conditions approaching and within the test section and bleed plenum, and those associated with the trace-gas system to measure the bleed flow rate.

\section{Test Section Instrumentation}

The flow condition entering the test section is determined from measurements of total pressure, total temperature, and dew point inside the wind tunnel plenum and with wall static pressure taps located near the exit plane of the C-D nozzle. Local conditions in the vicinity of the test article are measured with a translatable Pitot probe and wall static pressure taps on the upper and lower test section window inserts. A view of the flow side of the upper test section window insert is shown in Figure 6. With reference to Figure 6,18 surface static taps are located in the window insert and two are located on the test article itself. The taps are located along the centerline $(z=0)$ and at $z= \pm 2.22 \mathrm{~cm}(0.875 \mathrm{in}$.). The numbers beside the taps denote the port number of ESP pressure module number 5 that the taps were connected to. 
The Pitot probe shown in Figure 6 is remotely actuated in the $y$ and z-directions, but must be manually positioned in the $x$-direction (streamwise). For Phase I testing, only approach profiles in a transverse plane coinciding with the second row of static taps $(x=2.700 \mathrm{~cm}(1.065 \mathrm{in})$.$) were obtained. The tip of$ the Pitot probe is made from $0.508 \mathrm{~mm}(0.020 \mathrm{in}$.) tube flattened to $0.3302 \mathrm{~mm}(0.0130 \mathrm{in}$. $)$. The approximate position of the probe relative to the wall is established by an electrical touch circuit. The axial location of where the bleed hole centerline intersects the wall surface relative to the window leading edge varies depending on the bleed configuration and is shown in Figure 7.

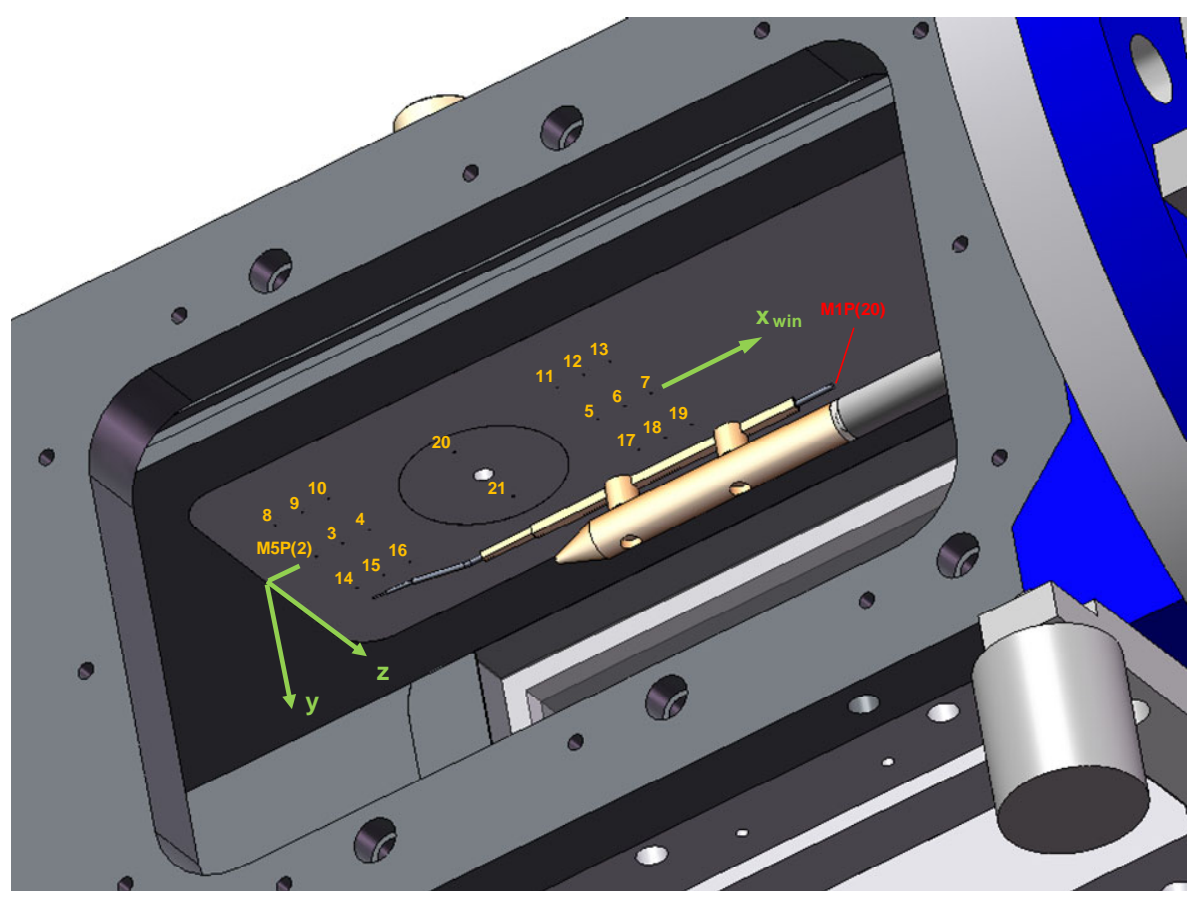

Figure 6.-Upper test section window insert instrumentation.

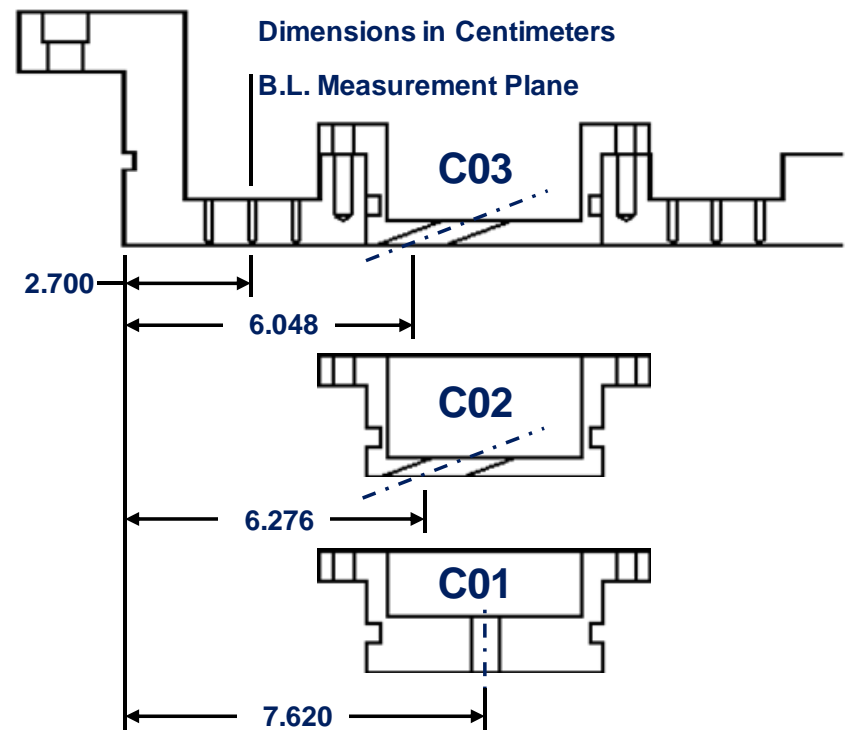

Figure 7.-Axial location of bleed holes. 


\section{Bleed Mass-Flow Measurement}

The bleed mass-flow rate is measured by the method of mixtures (Refs. 9 and 10) where the mixer gas is methane and its concentration is measured with a Flame Ionization Detector (FID). A schematic of the setup is shown in Figure 8. The bleed flow exits the bleed plenum through the male barb fitting installed in the plenum cover. Through a small port in the side of the barb fitting, methane is injected (Teledyne Hastings model HFC-302, 0 to $100 \mathrm{sccm}$ ) into the bleed flow at a known flow rate. The methane mixes with the bleed flow and a sample is delivered to the FID (Signal Instruments 3000 HM, 0 to $1000 \mathrm{ppm}$ ) which measures the methane concentration. Sample concentrations are typically maintained between 500 to $1000 \mathrm{ppm}$. The bleed flow rate can then be calculated from the following relation:

$$
w_{\text {air }}=\left(\frac{M_{\text {air }}}{M_{m e t}}\right) \cdot\left(\frac{1-v_{m e t}}{v_{m e t}}\right) \cdot w_{m e t}
$$

The bleed flow can also be routed through a calibrated electronic flow meter (Omega model FMA $875-\mathrm{V}, 0$ to $200 \mathrm{slm}$ range) which is used for measuring low bleed flow rates. Due to the low pressure in the bleed line, the flow meter will choke before the bleed hole does. The planned procedure for establishing a flow coefficient as a function of plenum pressure is to measure the bleed flow with the flow meter until it chokes. At this point the methane flow is established and the Omega flow meter bypass valve is opened. The bleed flow is then measured by the method of mixtures until the bleed hole chokes.

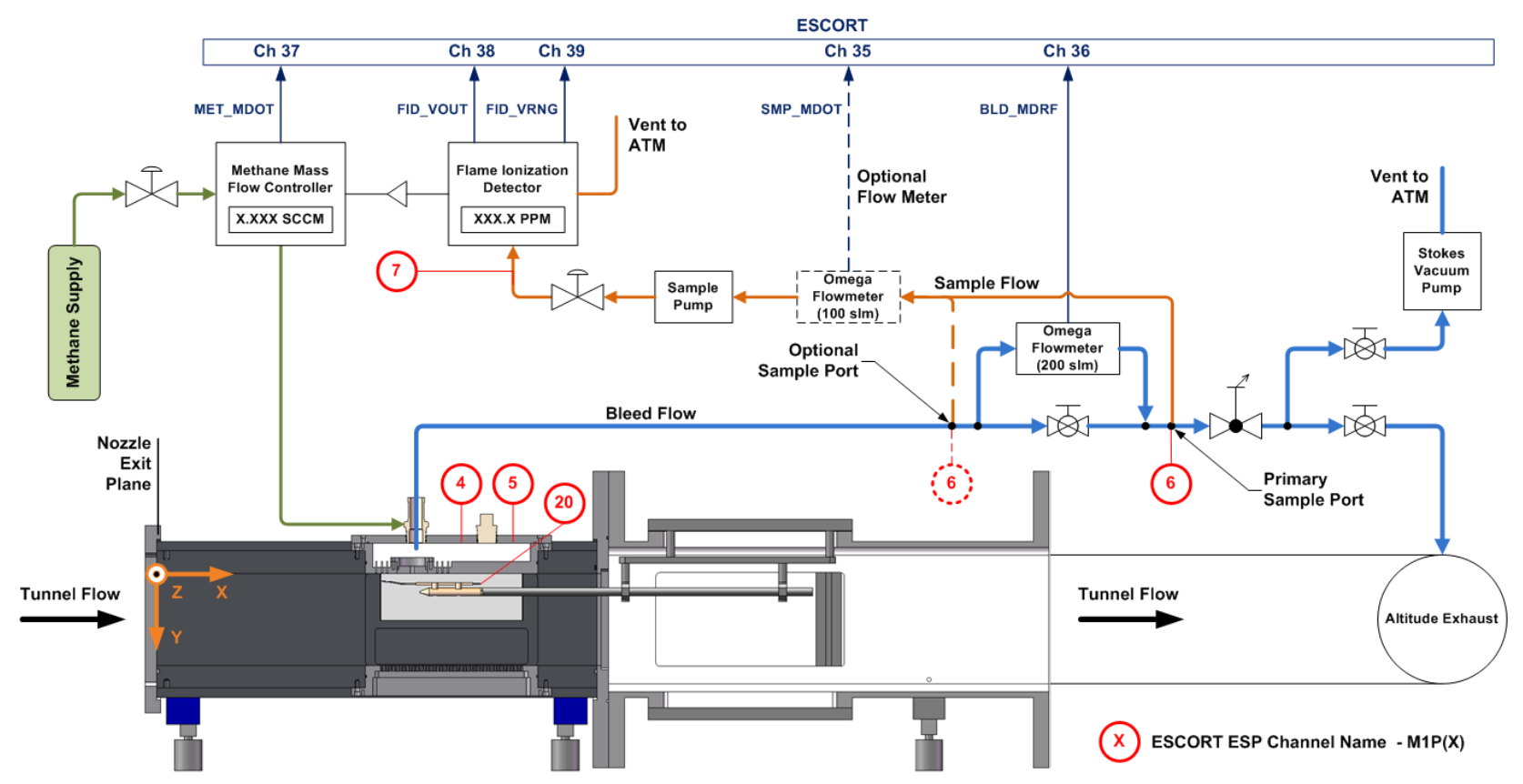

Figure 8.-The $15 \times 15 \mathrm{~cm}$ SWT test schematic. 
TABLE 1.-TEST OPERATING CONDITIONS $\left(\mathrm{RE}^{\prime}=\mathrm{RE} \times 1.0 \mathrm{E}-07 \mathrm{~m}\right)$

\begin{tabular}{|c|c|c|c|c|c|c|c|}
\hline Cond. no. & $\mathrm{M}_{\text {blk }}$ & $\mathrm{Re}^{\prime}$ & $\mathrm{M}_{\text {noz }}$ & $\mathrm{M}_{e}$ & $\begin{array}{c}\delta \\
(\mathrm{mm})\end{array}$ & $\begin{array}{c}\delta_{1} \\
(\mathrm{~mm})\end{array}$ & $H_{\text {inc }}$ \\
\hline 001 & 1.4 & 0.984 & 1.381 & 1.328 & 14.0 & 2.68 & 1.333 \\
\hline 002 & 1.4 & 1.89 & 1.387 & 1.334 & 14.0 & 2.55 & 1.324 \\
\hline 003 & 1.4 & 2.46 & 1.389 & 1.333 & 13.2 & 2.37 & 1.323 \\
\hline 004 & 1.7 & 0.984 & 1.671 & 1.617 & 12.5 & 2.75 & 1.341 \\
\hline 005 & 1.7 & 1.89 & 1.677 & 1.625 & 13.7 & 2.50 & 1.305 \\
\hline 006 & 1.7 & 2.46 & 1.679 & 1.618 & 12.3 & 2.41 & 1.320 \\
\hline 007 & 2.0 & 0.984 & 1.987 & 1.954 & 12.4 & 2.97 & 1.341 \\
\hline 008 & 2.0 & 1.89 & 1.992 & 1.966 & 12.2 & 2.77 & 1.326 \\
\hline 009 & 2.0 & 2.46 & 1.993 & 1.971 & 12.1 & 2.66 & 1.320 \\
\hline 010 & 2.5 & 0.984 & 2.493 & 2.455 & 14.2 & 3.92 & 1.344 \\
\hline 011 & 2.5 & 1.89 & 2.503 & 2.461 & 13.4 & 3.57 & 1.320 \\
\hline 012 & 2.5 & 2.46 & 2.506 & 2.463 & 13.1 & 3.44 & 1.311 \\
\hline 013 & 3.0 & 0.984 & 3.015 & 2.918 & 13.3 & 4.28 & 1.338 \\
\hline 014 & 3.0 & 1.89 & 3.031 & 2.956 & 12.5 & 3.99 & 1.316 \\
\hline 015 & 3.0 & 2.46 & 3.035 & 2.960 & 12.2 & 3.78 & 1.306 \\
\hline
\end{tabular}

\section{Operating Conditions}

Data were accumulated at nominal Mach numbers of 1.4, 1.7, 2.0, 2.5, and 3.0. At each Mach number, data were obtained at Reynolds numbers of $0.984,1.89$, and $2.46 \mathrm{E}+07 / \mathrm{m}(3.00,5.75$, and $7.50 \mathrm{E}+06 / \mathrm{ft}$ ). Thus, there were a total of 15 different conditions run. For bookkeeping purposes, a sequential number was assigned to each condition, which is summarized in Table 1. Also in Table 1 is the actual Mach number calculated at the nozzle exit plane as well as the local boundary-layer edge Mach number measured at the boundary-layer measurement plane shown in Figure 7. The distance from the nozzle exit to the boundary-layer measurement plane is $36.36 \mathrm{~cm}$ (14.32 in.) so that the edge Mach number is slightly below the nozzle exit Mach number.

\section{Approach Boundary-Layer Profiles}

Approach boundary-layer profiles were taken at an axial position of $x_{\text {win }}=2.700 \mathrm{~cm}$ (1.065 in.). This station coincides with the second axial row of pressure taps shown in Figure 6. For data reduction purposes, the static pressure was assumed to be constant across the boundary layer and equal to the average of the two taps on either side of the centerline (taps labeled M5P(9) and M5P(15) in Figure 6). The center tap, M5P(3), was directly under the probe and is influenced by the presence of the probe until it is well away from the wall. Beyond the point where the tap is no longer influenced, which is a function of Mach number, the center tap was in excellent agreement with the two outboard taps.

The measured boundary-layer profiles are plotted in terms of Mach number, normalized velocity, and in van Driest scaled variables (Ref. 11) (law-of-the-wall) in Figure 9. As expected, the profiles become fuller as the Reynolds number is increased indicating a reduction in displacement thickness. There are also two things to note about the Mach 3.0 profiles. First, is that the core flow is not uniform, and second, that the $\mathrm{Re}^{\prime}=0.984$ case does not recover to the same core Mach number as the higher Reynolds number cases. The flow quality of the Mach 3.0 block will be investigated further in the future. All of the profiles exhibit law-of-the-wall behavior indicating fully-turbulent boundary layers.

The calculated boundary-layer thickness, displacement thickness and incompressible shape factor for each operating condition is tabulated in Table 1. Note for current test articles, the bleed-hole diameter-todisplacement thickness $\left(D / \delta_{1}\right)$ is nominally $D / \delta_{1} \sim 2$, whereas traditionally for bleed systems this ratio is chosen to be closer to unity. The boundary-layer edge Mach number, displacement thickness, and incompressible shape factor are plotted as a function of nozzle Mach number for the various Reynolds numbers in Figure 10. The boundary-layer edge Mach number is largely independent of Reynolds number except for the aforementioned lower core Mach number for the lowest Reynolds number case at Mach 3.0. The displacement thickness decrease with increasing Reynolds number is as expected. 


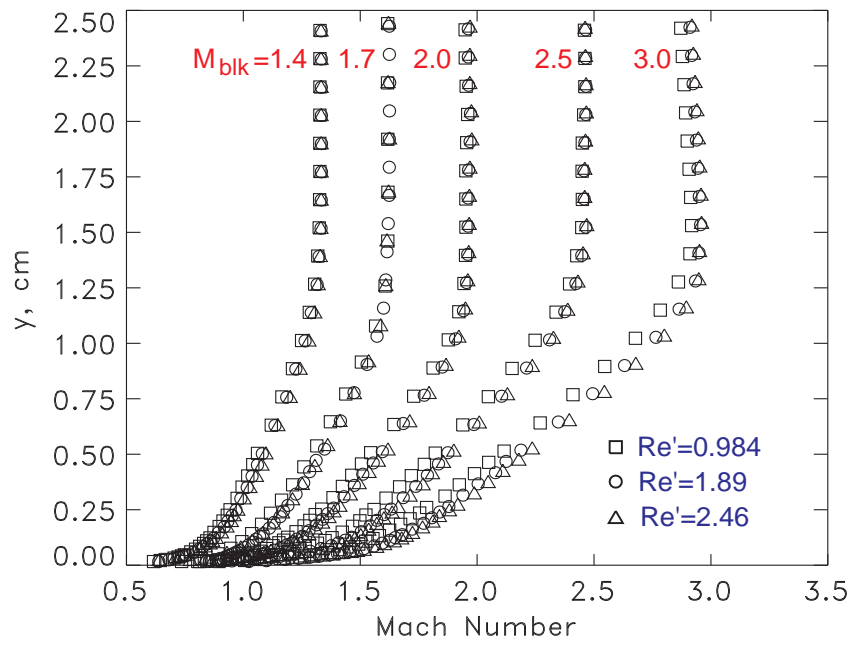

a) Mach number profiles.

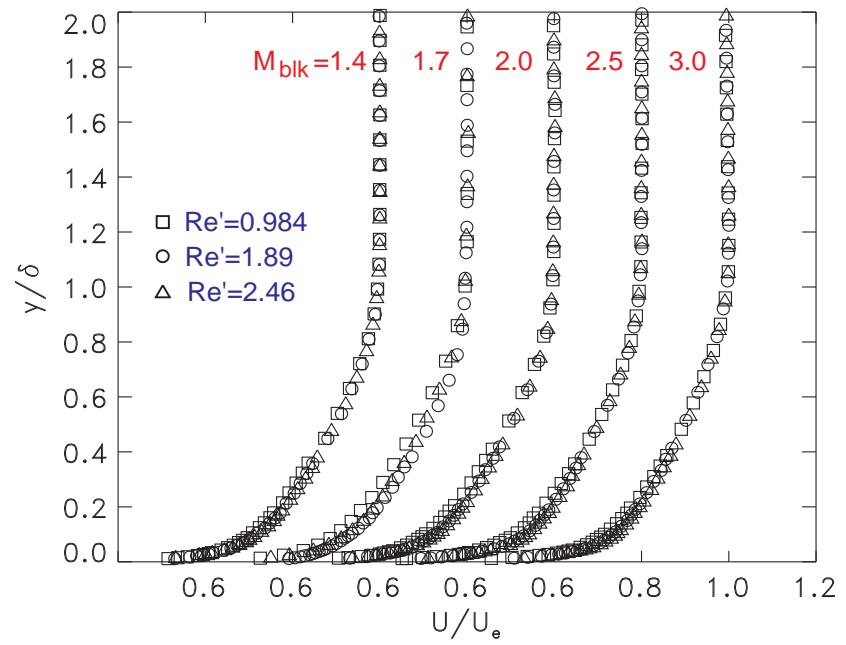

b) Normalized velocity profiles.

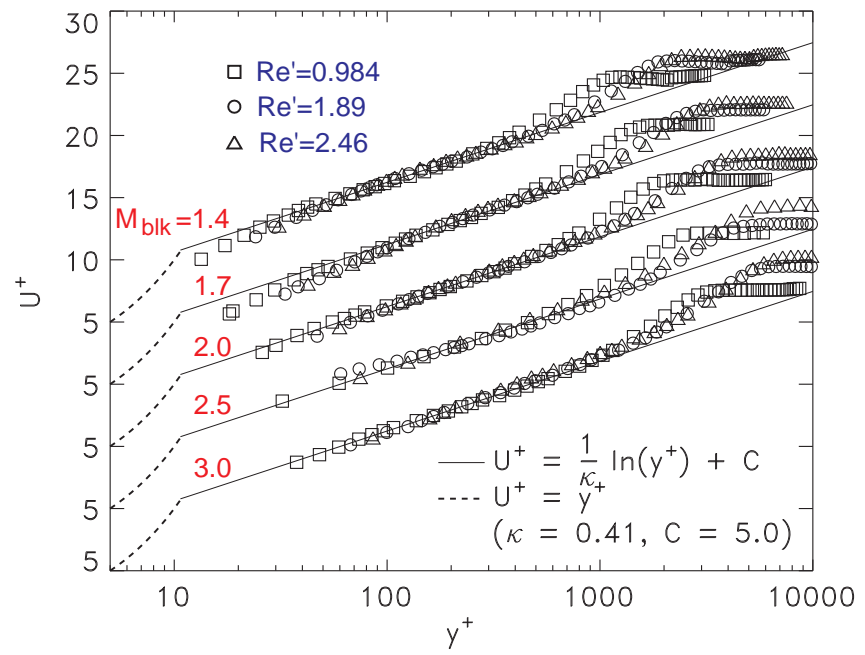

c) Van driest scaled profiles.

Figure 9.-Approach boundary-layer profiles.

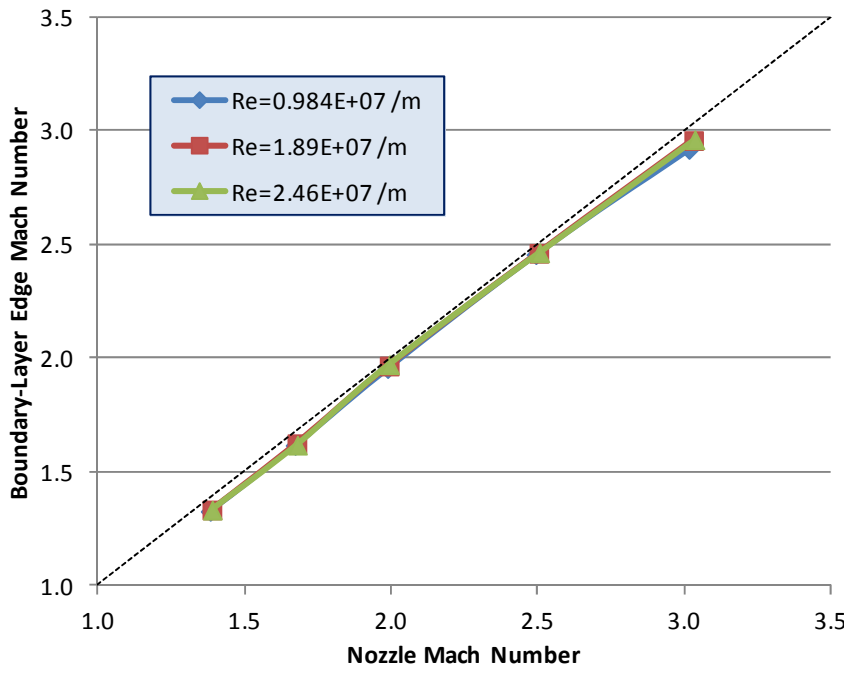

a) Boundary-layer edge Mach number.

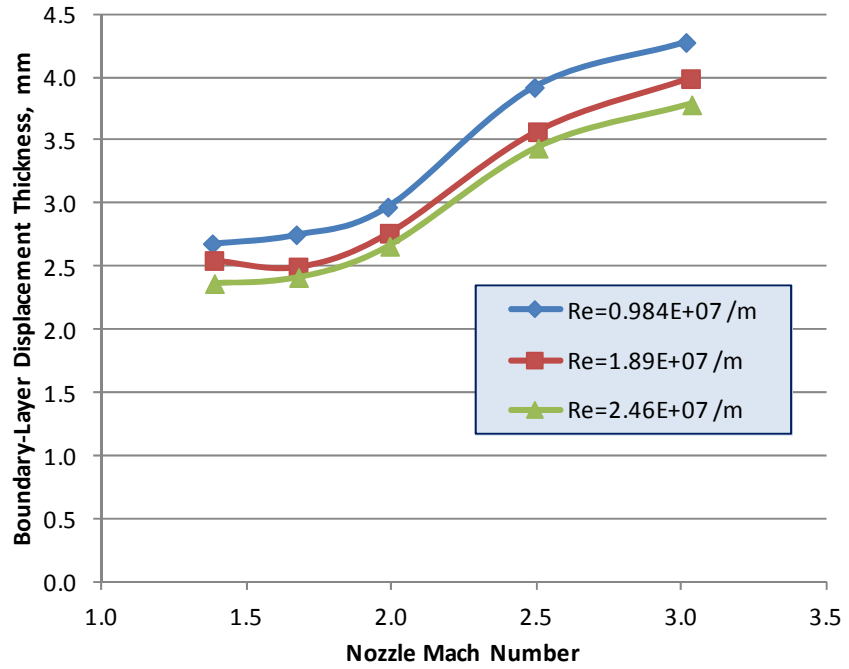

b) Displacement thickness.

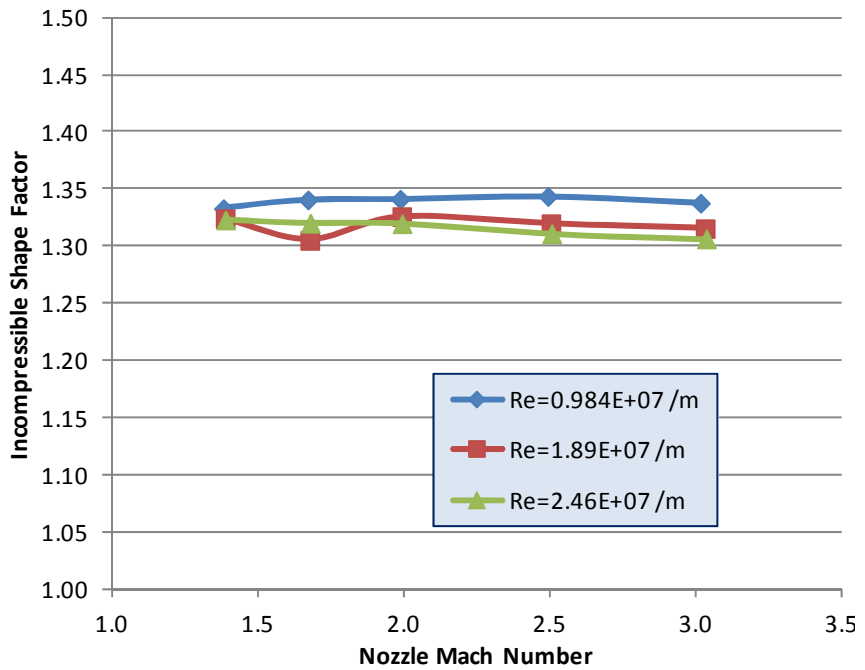

c) Incompressible shape factor.

Figure 10.-Approach boundary-layer parameters. 
Although some dependence on Mach number was anticipated, the S-shaped trend with Mach number was not expected and is not fully understood. The incompressible shape factor is relatively independent of Mach number and varies with Reynolds number in a manner expected. The nominal value of 1.32 for all the profiles is consistent with a fully-turbulent compressible boundary layer.

\section{Flow Coefficient Data}

Flow coefficient data were obtained with the $\mathrm{C} 01$ and $\mathrm{C} 02$ configurations at the conditions listed in Table 1. Flow coefficient data are typically presented in terms of a sonic flow coefficient defined as:

$$
Q=\frac{w}{w_{i}^{*}}
$$

where the numerator is the measured mass-flow rate and the denominator is the ideal mass-flow rate under choked conditions:

$$
w_{i}^{*}=\frac{\left(P_{t, e} \cdot A_{b}\right)}{\sqrt{T_{t, e}}} \cdot \sqrt{\frac{\gamma \cdot g_{c}}{R_{\mathrm{air}}}} \cdot\left(\frac{\gamma+1}{2}\right)^{\left(\frac{-(\gamma+1)}{2 \cdot(\gamma-1)}\right)}
$$

The sonic flow coefficient is typically presented as a function of the ratio of bleed plenum pressure to freestream (boundary-layer edge) total pressure $\left(P_{\text {plen }} / P_{t, e}\right)$. The total temperature at the boundary-layer edge $\left(T_{t, e}\right)$ is assumed to be the same as the total temperature in the wind tunnel plenum chamber $\left(T_{t, 0}\right)$.

With reference to Figure 8, a typical flow coefficient curve was obtained by initially passing all the bleed flow through the calibrated electronic flowmeter. The bleed control valve is opened and data recorded until the flow meter chokes. At this point, the bleed control valve is closed slightly, the bypass valve is opened, and methane flow is established. The measurements are then continued with the trace gas system by opening the bleed valve, recording the methane flow rate and concentration, and then calculating the mass flow via Equation (5). The bleed control valve was typically backed-off so as to establish a measure of overlap from the two measurement techniques.

Initial checkout of the trace gas system was performed at Mach zero conditions for the three bleed configurations as shown in Figure 11. In this figure, the solid symbols are the results from the electronic flowmeter and the open symbols are the results from the trace gas system. Under these conditions, the agreement between the two methods is observed to be very good. All three configurations initially exhibit similar behavior as the plenum pressure is reduced. With reference to Figure 7, the $\mathrm{C} 03$ configuration, which turns the flow the full $70^{\circ}$ to flow normal to the minimum area, lags behind $\mathrm{C} 01$ and $\mathrm{C} 02$ configurations, but eventual chokes at the same level $(Q \sim 0.8)$ as the $\mathrm{C} 01$ configuration. The $\mathrm{C} 02$ configuration, which turns the flow $57^{\circ}$ to flow normal to the minimum area, follows the $\mathrm{C} 01$ closely then deviates where it chokes at a flow coefficient near unity. The approximately 25 percent higher flow coefficient is consistent with the minimum area being about 25 percent higher than the hole area for $t / D=0.684$ and $\alpha=20^{\circ}$.

Under flow conditions, the agreement between the two methods was not as good. Figure 12 shows flow coefficient distributions for the $\mathrm{C} 01$ configuration at $\mathrm{M}_{b l k}=1.4$ at the three Reynolds numbers tested, although all Mach numbers tested displayed similar behavior. The overlaid curves to the far right show the trace gas results for all three Reynolds numbers. The flowmeter and trace gas results are then presented to the left on shifted scales so the difference between the two techniques can be discerned. 


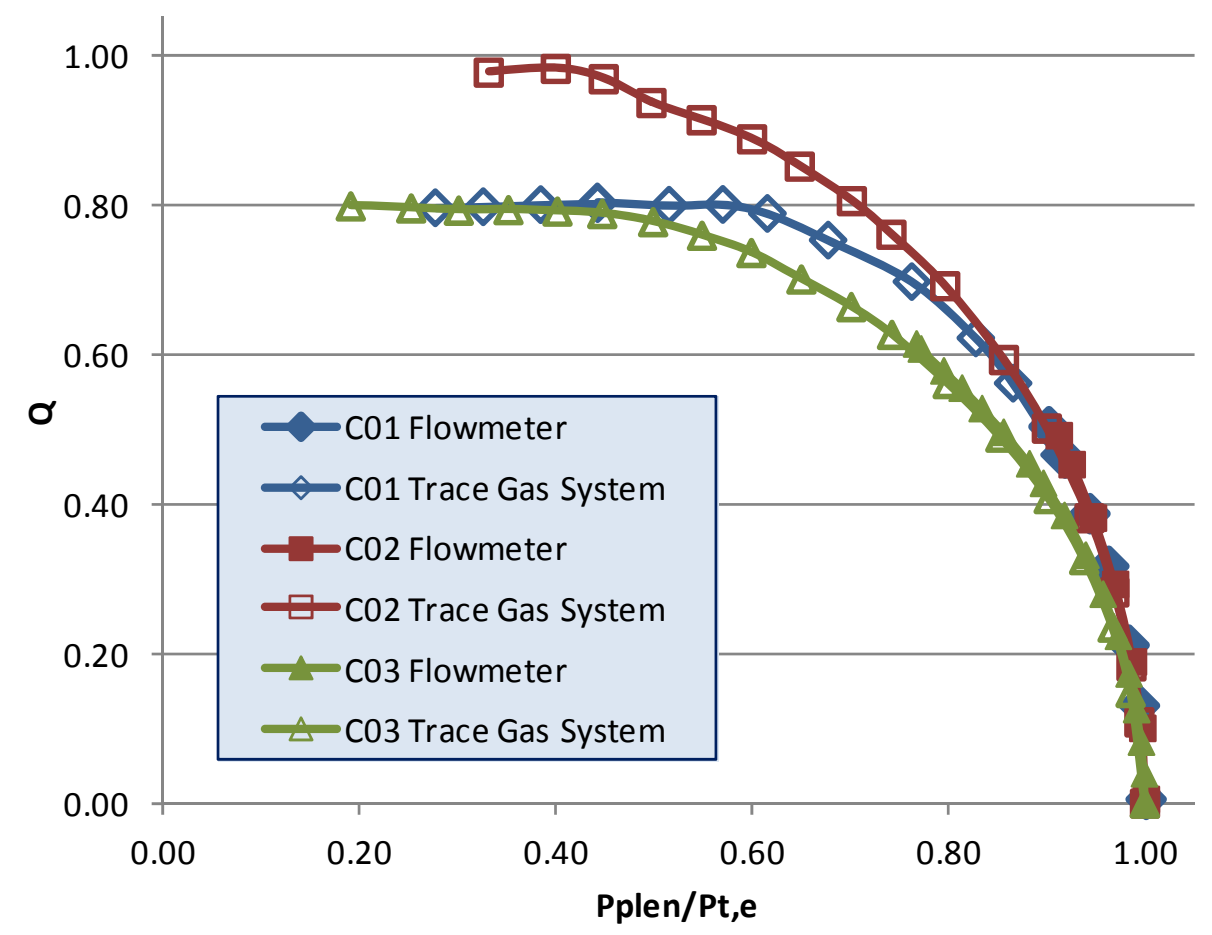

Figure 11.-Flow coefficient for Mach zero condition.

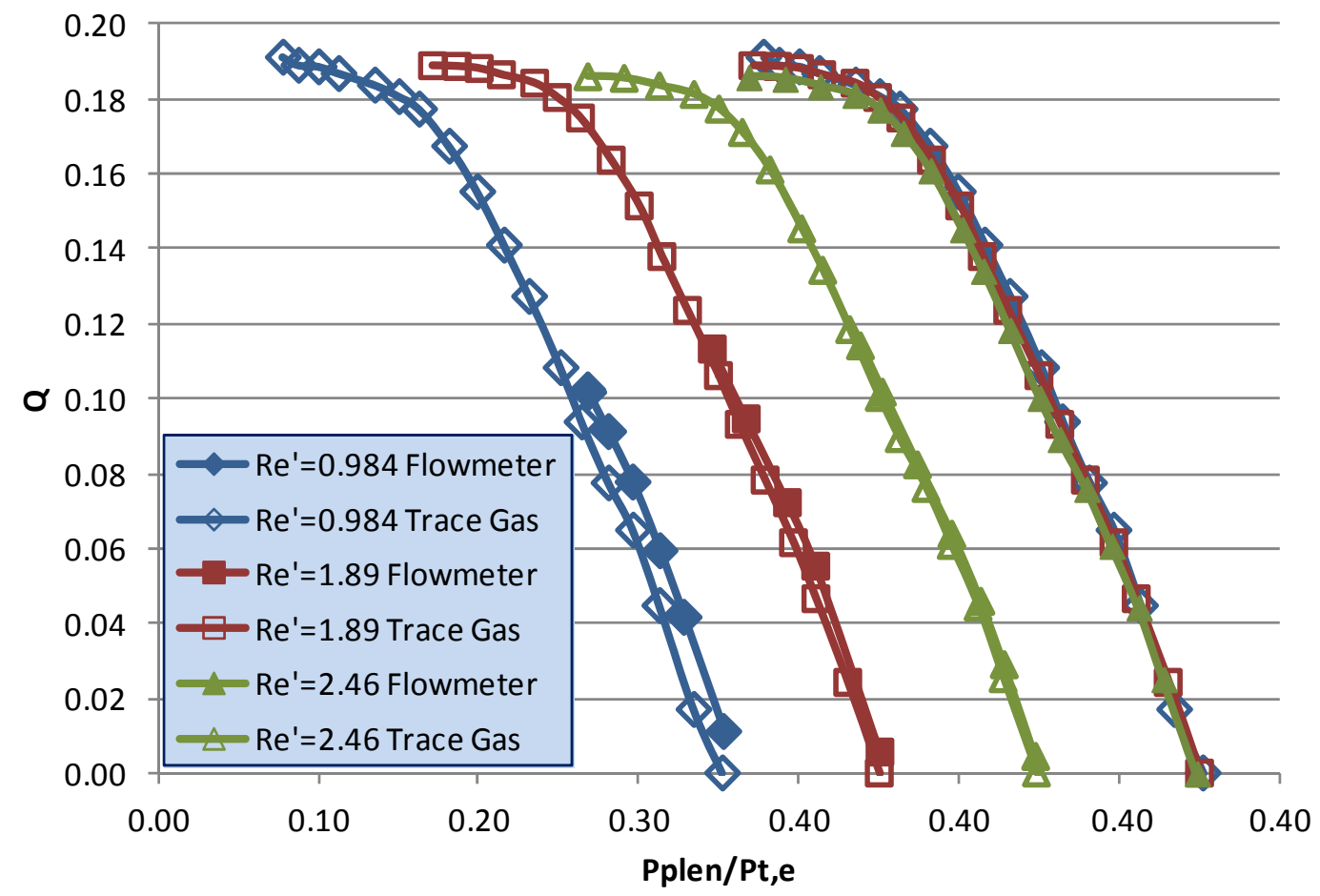

Figure 12.-Comparison of electronic flowmeter and trace gas system for $\mathrm{C01}$ at $\mathrm{M}_{b l k}=1.4$. 
For the case presented, trace gas results were obtained which fully overlapped the electronic flowmeter results. The first thing of note is that the electronic flowmeter reads a slight positive flow when put under vacuum conditions even when there was no bleed flow. These points are the solid symbols furthest to the right in the plots. Whereas the trace gas results (far right curves) are relatively independent of Reynolds number, at least in the lower flow range, the electronic flowmeter shifts increasingly to the right as the Reynolds number is reduced (decreasing bleed line pressures). This suggests that there is a Reynolds number effect on the calibration of the flowmeter. Prior to testing, the flowmeter was calibrated at approximately between one and two atmospheres. Under flow conditions the bleed line pressure varied between 1.7 to $55 \mathrm{kPa}(0.25$ to $8.0 \mathrm{psia})$. The reason for using the electronic flowmeter was to avoid having to use multiple range methane flow controllers to resolve the lower flow rates as well as the improved response time over the trace gas system at low flow rates. Two improvements will be considered for future testing. First, multiple methane flow controllers of different ranges that can be remotely switched in and out of the circuit will be added to ensure that the methane flow rate is appropriate for the bleed flow rate (resulting concentration between 500 to $1000 \mathrm{ppm}$ ), and second, the electronic flow meter, which was calibrated at above atmospheric conditions, will be calibrated under vacuum conditions. Inasmuch as it appears that the electronic flowmeter was being operated outside the range of its calibration, only the trace gas results will be presented from here forward. This means that the lower flow rates won't be resolved as well as they otherwise might have been.

Subsequent to the accumulation of the current flow coefficient data, flow coefficient data at Mach 2.46 from Bodner et al. (Refs. 5 and 6) was located. In this study, Bodner used the same bleed plugs in the same facility but used a sidewall of the tunnel rather than the top wall of the tunnel. The same electronic flowmeter/method-of-mixtures technique was used to obtain his data, but the gas bench was comprised of all different components. A comparison of these data with the current data at $\mathrm{M}=2.46$ is shown in Figure 13. For the C02 case (Fig. 13(b)), the data are in very good agreement. For the C01 configuration (Fig. 13(a)), the trends are the same but Bodner's curve has a higher slope than the present data. After this discrepancy was discovered, the present $\mathrm{C} 01$ data were repeated with the same results. Inasmuch as the present data were carefully repeated and reviewed with no anomalies discovered, it is assumed here that the present data are correct.

The flow coefficient distributions for all of the operating conditions are shown in Figure 14. With reference to Figure 14(a), a feature of note is the tail-up behavior at the left end of the curves, primarily at the lower Reynolds numbers. This behavior is attributed to the inability of the sample pump to provide the sample at a sufficient flow rate to the FID unit. Much of the data were accumulated with a single stage vacuum pump that failed midway through the investigation. It was replaced temporarily with a borrowed two-stage pump, and then ultimately a new four stage pump was installed. There was not time to repeat these curves with the four stage pump, but some spot checks of the data indicated that the problem will be resolved at all conditions but the low Reynolds number cases at Mach 2.5 and 3.0.

With reference to Figure 14(b), the behavior of the $20^{\circ}$ hole is markedly different than the $90^{\circ}$ hole. At zero flow rates, there is a slight pressurization of the bleed plenum. At low flow rates, the plenum pressure is observed to be invariant with flow rate. As the flow approaches a choked condition (upper part of the curves), the lowest Reynolds number data are observed to ride below the higher two cases except for the lowest Mach number case $\left(\mathrm{M}_{b l k}=1.4\right)$. For this case only, the curve is shifted to the right. The reason for the shift is not yet known, but it is repeatable.

The low Reynolds number data were taken to exercise the system over as large of a range as possible, but practically speaking it isn't as of much interest as the higher Reynolds number data. If we exclude the low Reynolds number data for both the $\mathrm{C} 01$ and $\mathrm{C} 02$ configurations, then the remaining two Reynolds number cases agree fairly well. While there is no definite trend observed for the C01 configuration, the C02 configuration consistently shows slightly higher flow rates as the Reynolds number increases. 


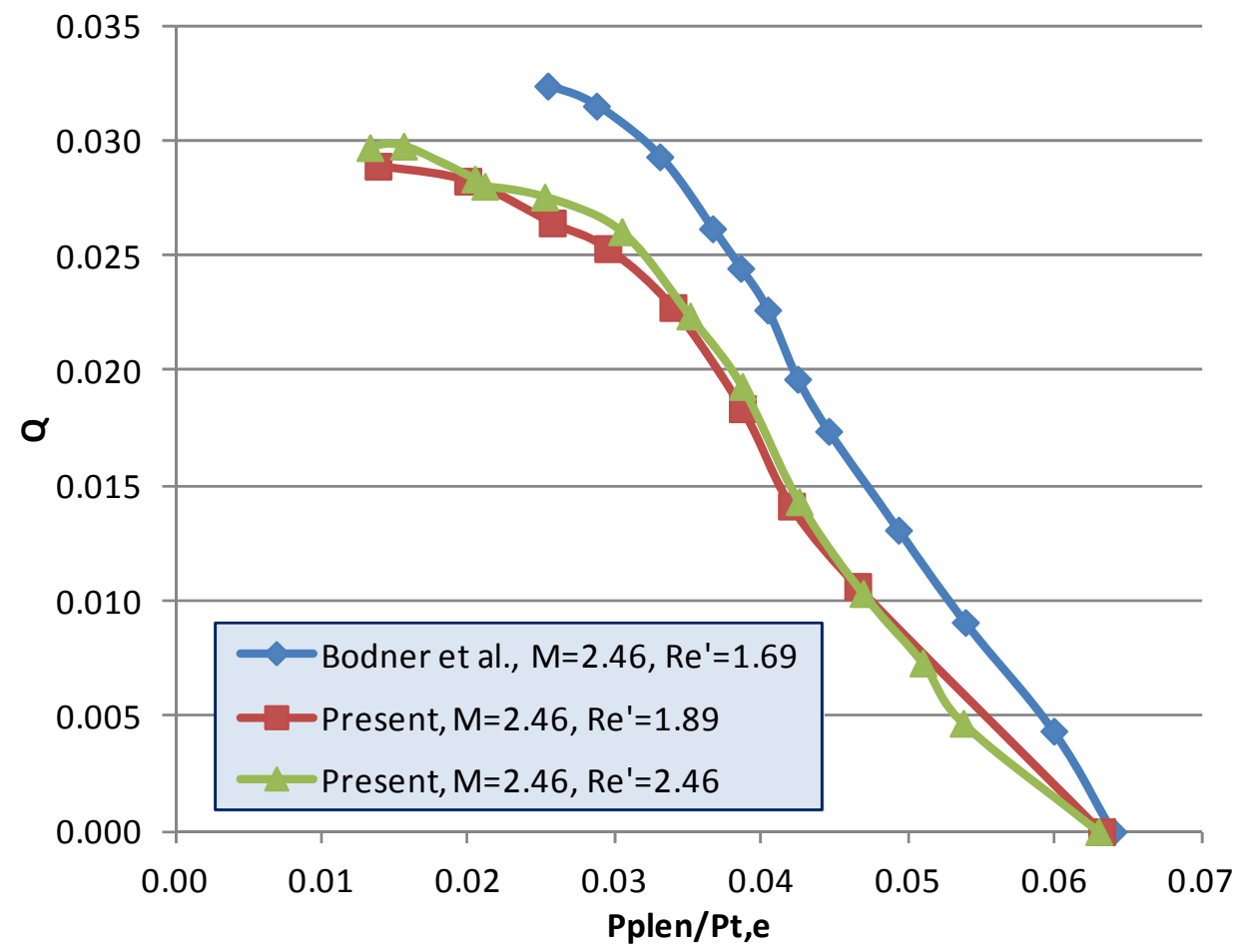

a) C01 bleed configuration ( $90^{\circ}$ hole)

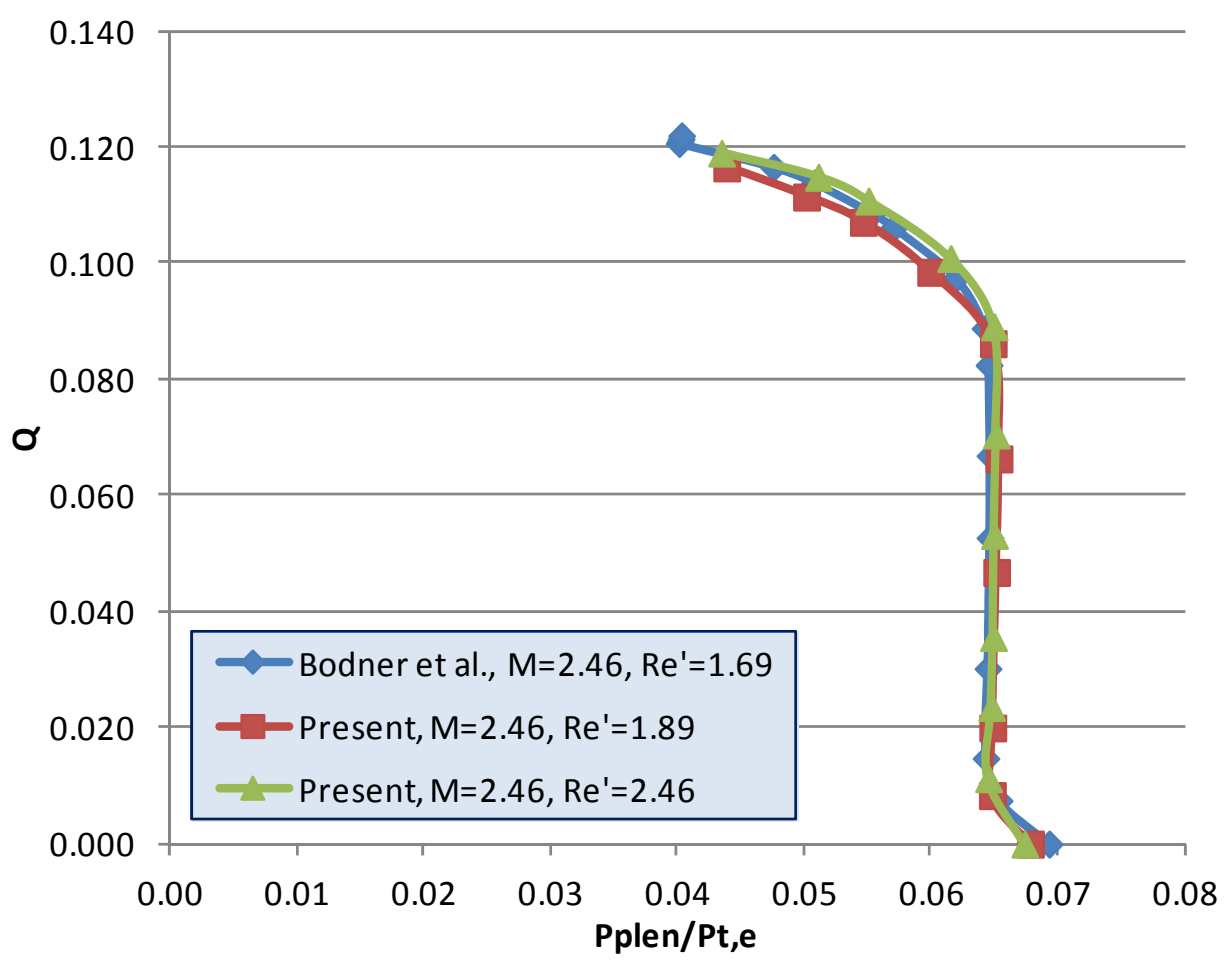

b) $\mathrm{C} 02$ bleed configuration $\left(20^{\circ}\right.$ hole $)$

Figure 13. - Comparison of flow coefficient with data from Bodner et al. at $\mathrm{M}=2.46$. 


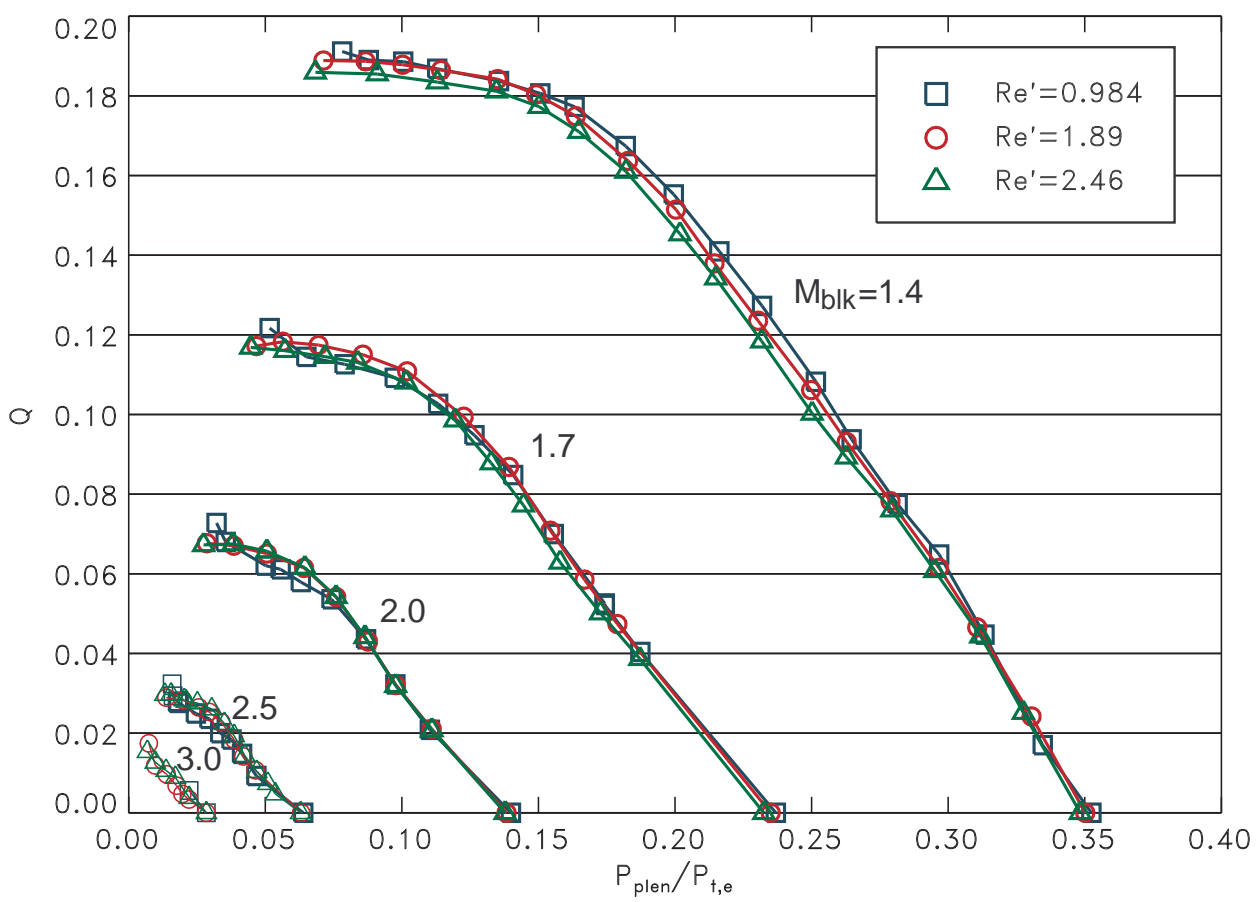

a) C01 bleed configuration

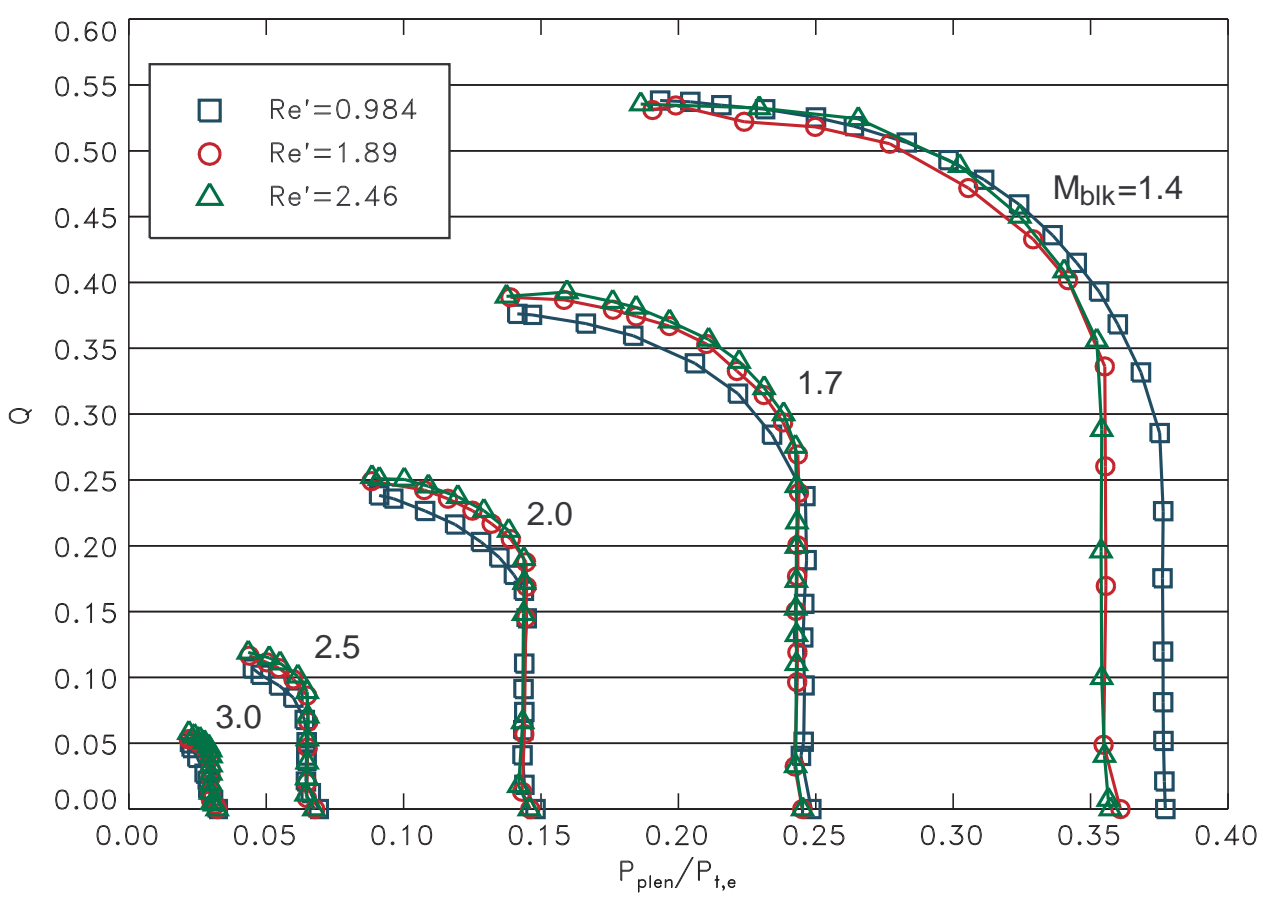

b) C02 bleed configuration

Figure 14.- Sonic flow coefficient as a function of normalized bleed plenum pressure. 
TABLE 2.-PARAMETERS OF BLEED CONFIGURATIONS

OF WILLIS et al. (REF. 2)

\begin{tabular}{|l|c|c|}
\hline \multicolumn{1}{|c|}{ Variable } & $\mathrm{C} 1$ & $\mathrm{C} 3$ \\
\hline$\alpha($ degrees $)$ & 90.0 & 20.0 \\
\hline$D(\mathrm{~mm})$ & 6.35 & 6.35 \\
\hline$L / D$ & 1.0 & 2.92 \\
\hline$D / \delta_{1}$ & $\sim 1.0$ & $\sim 1.0$ \\
\hline No. of holes & 75 & 75 \\
\hline No. of rows & 6 & 6 \\
\hline No. of columns & 12.5 & 12.5 \\
\hline$x / D$ spacing & 2.0 & 2.78 \\
\hline z/D spacing & 2.0 & 2.0 \\
\hline Porosity (percent) & 19.6 & 14.1 \\
\hline
\end{tabular}

The present data for $\mathrm{Re}^{\prime}=1.89$ were compared with the multi-hole data of Willis et al. (Ref. 2). The configurations compared are the $\mathrm{C} 1\left(\alpha=90^{\circ}\right)$ and $\mathrm{C} 3\left(\alpha=20^{\circ}\right)$ bleed plates of Willis et al. The parameters of these plates are summarized in Table 2 . The data were accumulated at similar Mach numbers $\left(\mathrm{M}_{e}=1.27,1.58,1.98,2.46\right)$ to the present test. Notable differences between the present hole parameters and those in the Willis plates are $D / \delta_{1}$ and $L / D$. The comparison of the flow coefficient curves are shown in Figure 15. With reference to Figure 15(a), the data trends are very similar with the exception that the single-hole data tend to show a more defined choke at a lower level than that of the multi-hole data. This is best illustrated by the Mach 2.0 cases, where the edge Mach numbers are almost the same and the curves are nearly coincident until the choke points are reached. The present Mach $2.0\left(\mathrm{M}_{e}=1.97\right)$ data would be expected to be slightly to the right of the multi-hole Mach 2.0 $\left(\mathrm{M}_{e}=1.98\right)$ data, but the larger $L / D$ ratio of the single-hole would tend to move it back to the left. The higher choke point of the multi-hole data implies that each successive row of holes sees a slightly larger local pressure. The present data at $\mathrm{M}=2.5$ is also similar but shifted slightly to the left which is likely due to the higher hole length-to-diameter ratio. For the C02 configuration (Fig. 13(b)), the difference between the choke level is still evident, but to a much smaller degree. The Mach 2.0 and 2.5 data agree well with the multi-hole data of Willis. The more significant difference between the distributions is in the subcritical flow region (low flow rates) where the pressurization of the bleed plenum is much more pronounced for the multi-hole configuration. 


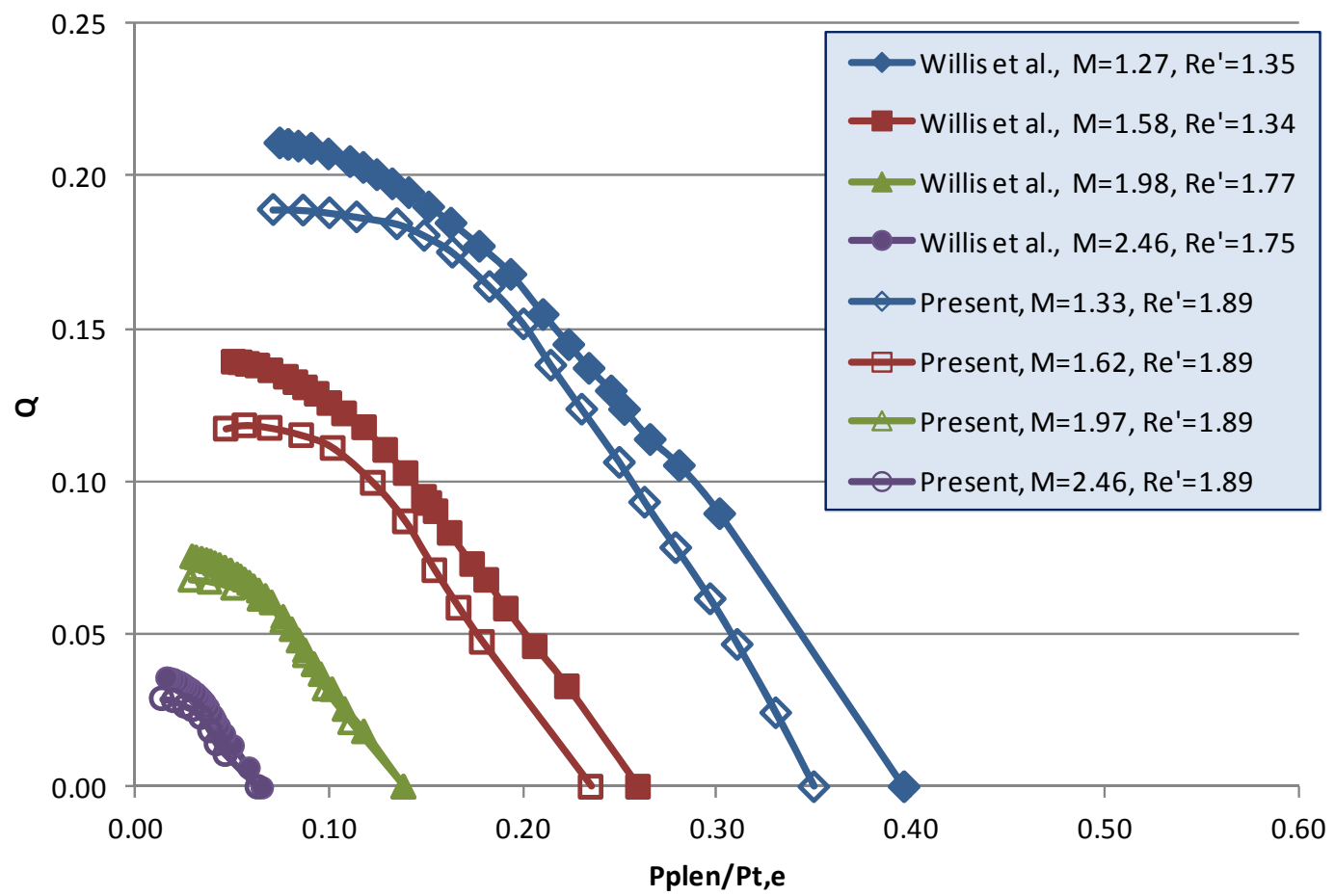

a) C01 bleed configuration $\left(\alpha=90^{\circ}\right)$

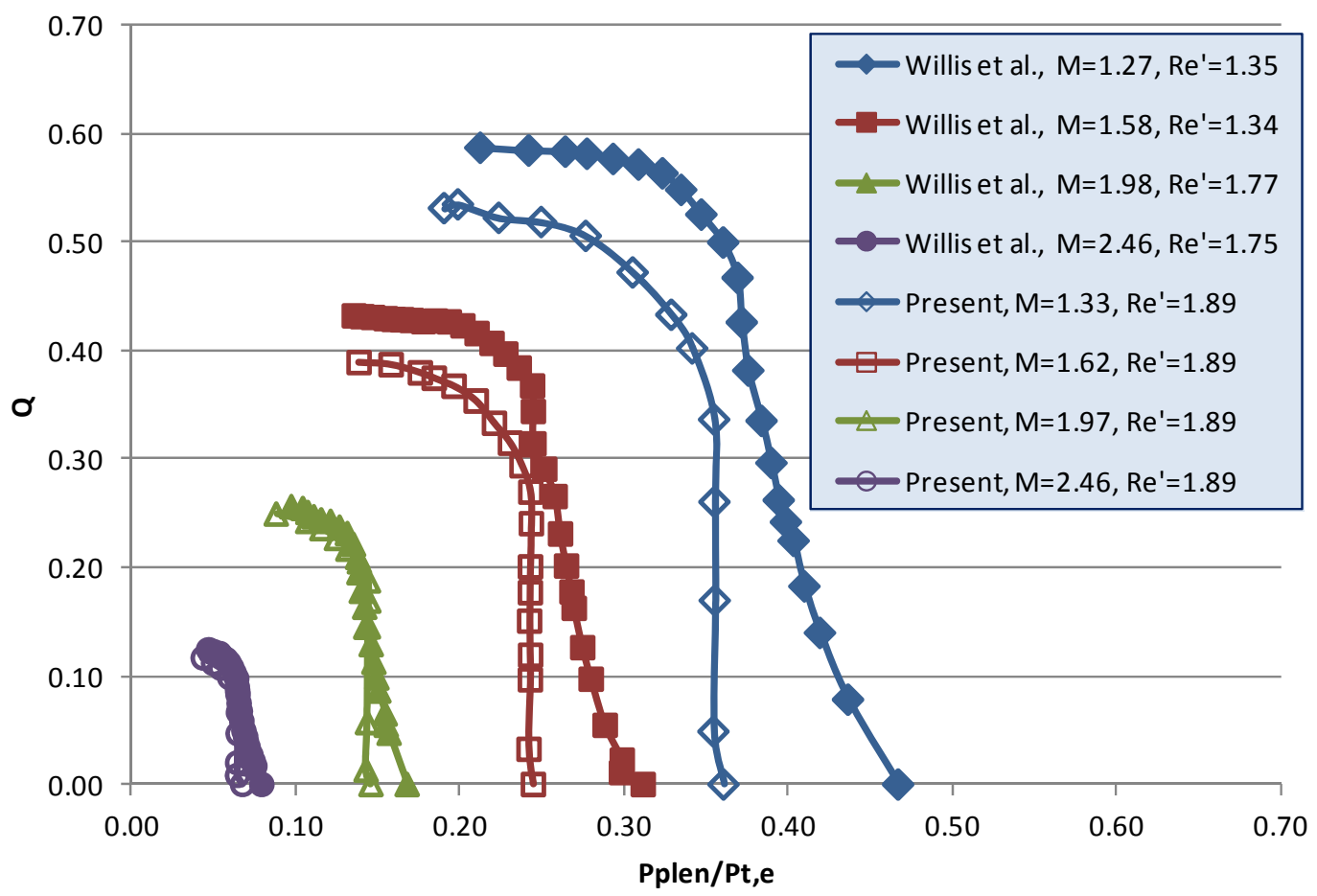

b) C02 bleed configuration $\left(\alpha=20^{\circ}\right)$

Figure 15.-Present data compared to data of Willis et al. 


\section{Flow Coefficient Scaling}

The similarity of the curves for the different Mach numbers has led the authors to seek a scaling that would collapses the curves to a single distribution. Initial efforts by Davis (Ref. 4) and Slater (Ref. 1) focused on the $90^{\circ}$ data of Willis et al. Both investigators took the approach of normalizing the bleed plenum pressure by the local surface static pressure, but Davis also included a coefficient to account for the slight overpressure of the bleed plenum at zero flow rates. For scaling the flow coefficient, the investigators took different approaches. Whereas Slater assumed for the $90^{\circ}$ hole case that the total pressure in the hole was approximately equal to the local surface static pressure, Davis established a purely empirical scaling based on the extrapolated choked value of the bleed plate. Slater's correlation takes the form of:

$$
Q_{\text {scaled }}=0.59799735+0.03069346 \cdot\left(P_{\text {plen, scaled }}\right)-0.59361420 \cdot\left(P_{\text {plen, scaled }}\right)^{2}
$$

where

$$
P_{\text {plen }, \text { scaled }}=\frac{\left(\frac{P_{\text {plen }}}{P_{t, e}}\right)}{\left(\frac{P_{w}}{P_{t, e}}\right)}=\frac{\left(\frac{P_{\text {plen }}}{P_{t, e}}\right)}{\left(1+\frac{\gamma-1}{2} \cdot \mathrm{M}_{e}^{2}\right)^{\frac{-\gamma}{\gamma-1}}}
$$

and

$$
Q_{\text {scaled }}=\frac{Q}{\left(\frac{P_{w}}{P_{t, e}}\right)}=\frac{Q}{\left(1+\frac{\gamma-1}{2} \cdot \mathrm{M}_{e}^{2}\right)^{\frac{-\gamma}{\gamma-1}}}
$$

and Davis' scaled correlation takes the form of:

$$
Q_{\text {scaled }}=-0.74177271+\frac{1.7397157}{\left(1+\left(\frac{P_{\text {plen }, \text { scaled }}}{0.91473254}\right)^{3.2074431}\right)}
$$

where

$$
P_{\text {plen }, \text { scaled }}=\frac{\left(\frac{P_{\text {plen }}}{P_{t, e}}\right)}{1.059 \cdot\left(\frac{P_{w}}{P_{t, e}}\right)}=\frac{\left(\frac{P_{\text {plen }}}{P_{t, e}}\right)}{1.059 \cdot\left(1+\frac{\gamma-1}{2} \cdot \mathrm{M}_{e}^{2}\right)^{\frac{-\gamma}{\gamma-1}}}
$$

and

$$
Q_{\text {scaled }}=\frac{Q}{\left(-6.885241-5.9569877 \cdot \mathrm{M}_{e}^{2}+5.9532869 \cdot e^{\mathrm{M}_{e}}\right)}
$$


Willis' data scaled by both methods and the above correlations derived from these data are shown in Figure 16. Both methods collapse the $90^{\circ}$ data fairly well. To illustrate deviations of the present singlehole data, the present data are compared to these above correlations in Figure 17. This plot shows Slater's correlation fits the present data better which isn't unexpected since Davis' correlation was based on an empirical fit of the extrapolated choke points of the multi-hole data. Slater's correlation seems to fit the lower Mach number data better with increasing deviation as the Mach number is increased. However, even the lowest Mach number data deviation from the Slater correlation near the choke point, implying that an adjustment for the number of bleed hole rows, and potentially the hole spacing, may be required.

Finally, the $20^{\circ}$ present single-hole and multi-hole data of Willis are plotted scaled by the parameters suggested by Slater (Eqs. (9) and (10)) in Figure 18. For low flow rates $\left(Q_{\text {scaled }}<1.0\right)$, it is clear that the single and multi-hole data have a significantly different behavior. It is also evident that the single-hole distributions choke at slightly lower values than the multi-hole data, but more significantly the choked data do not collapse as well as the $90^{\circ}$ data. This suggests that the assumption that the total pressure in the hole is equal to the surface static is not valid for shallow angled holes. This is expected since the shallow angled holes do not produce a strong barrier shock like the steeper angled holes do. Developing a correlation that includes the effect of hole angle will require additional data at intermediate hole angles which will be the subject of future work.

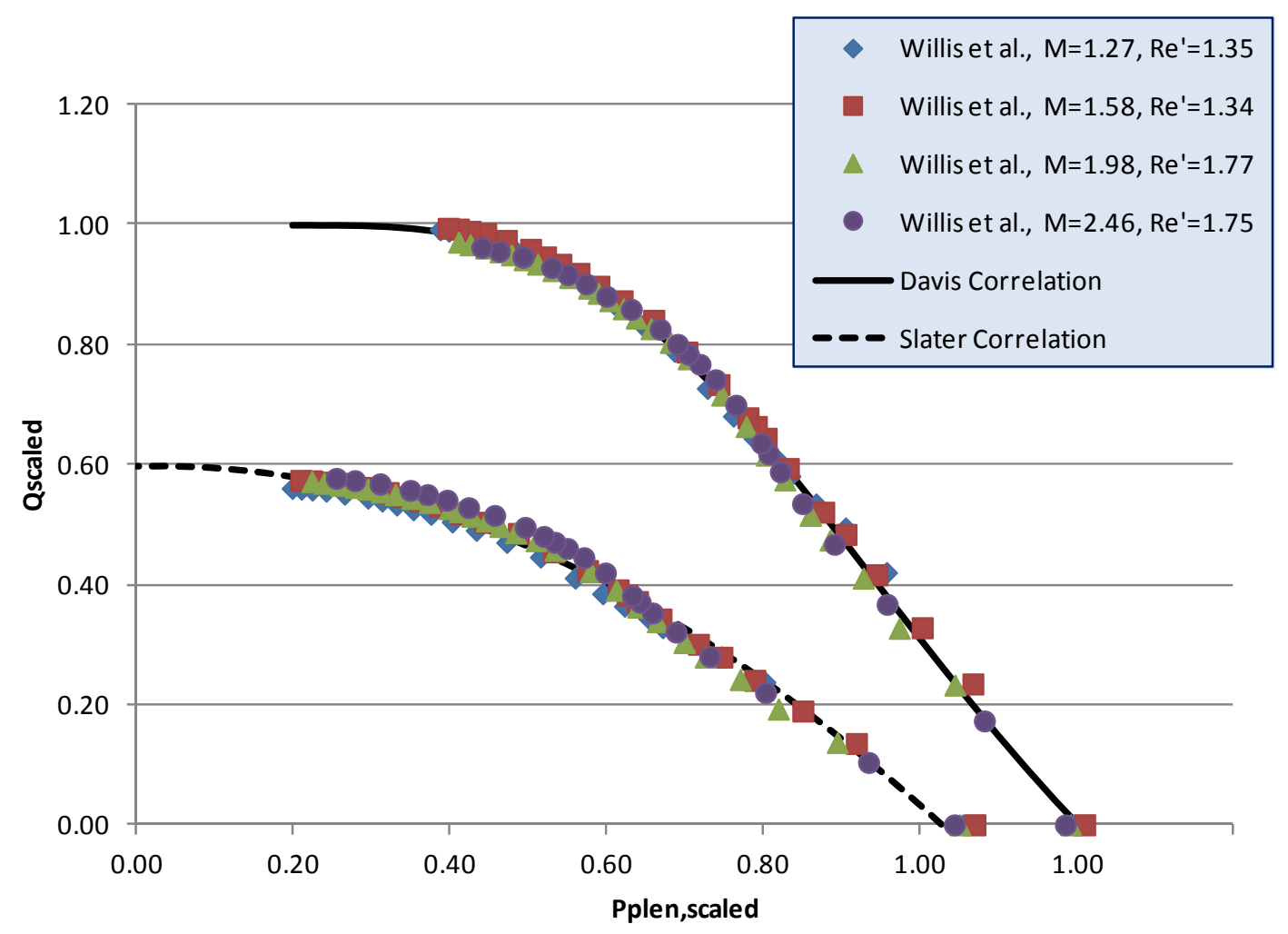

Figure 16.-Correlations of Davis and Slater derived from $90^{\circ}$ multi-hole data of Willis et al. 


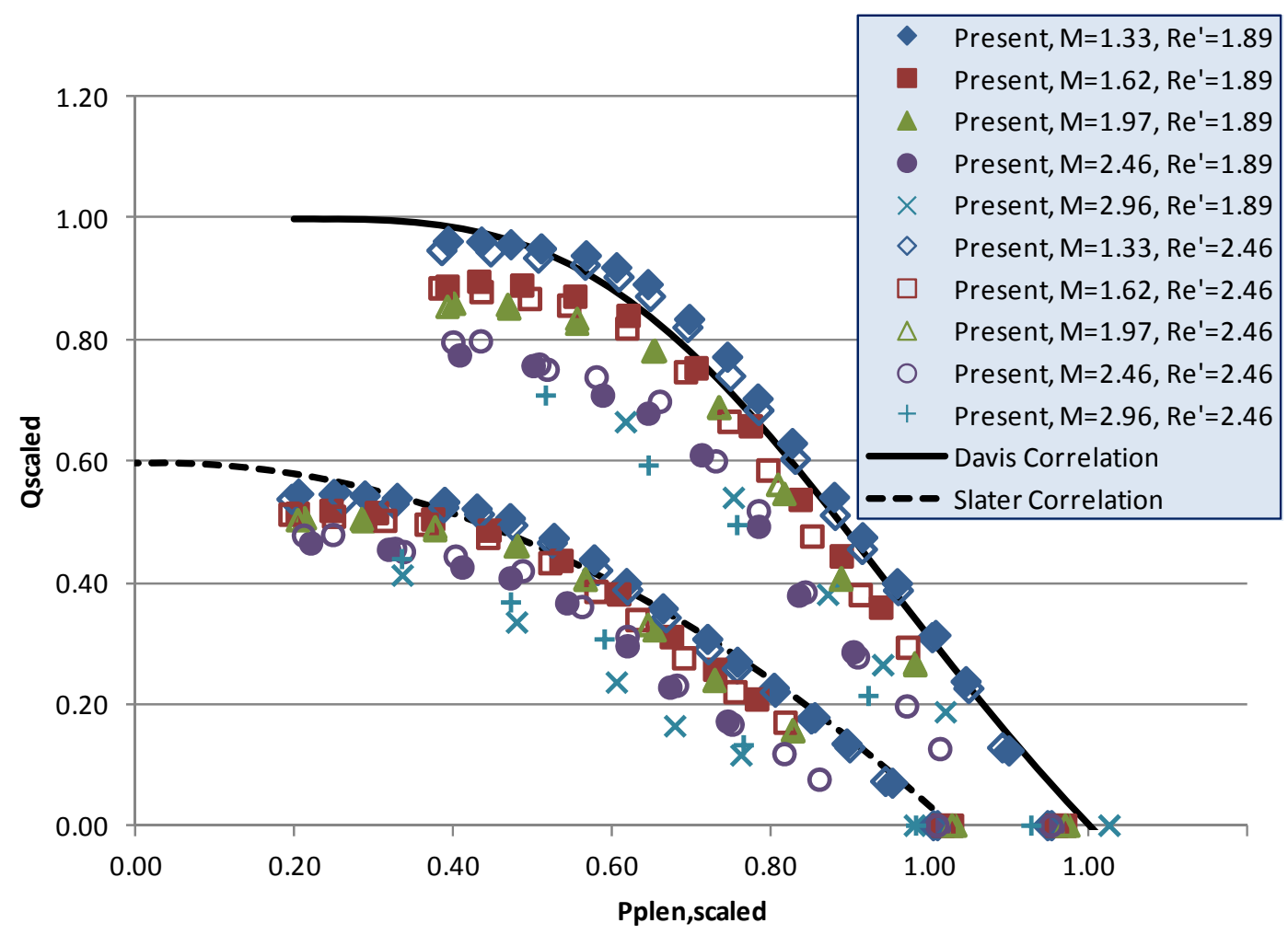

Figure 17.-Comparison of present $90^{\circ}$ hole data to correlations of Davis and Slater.

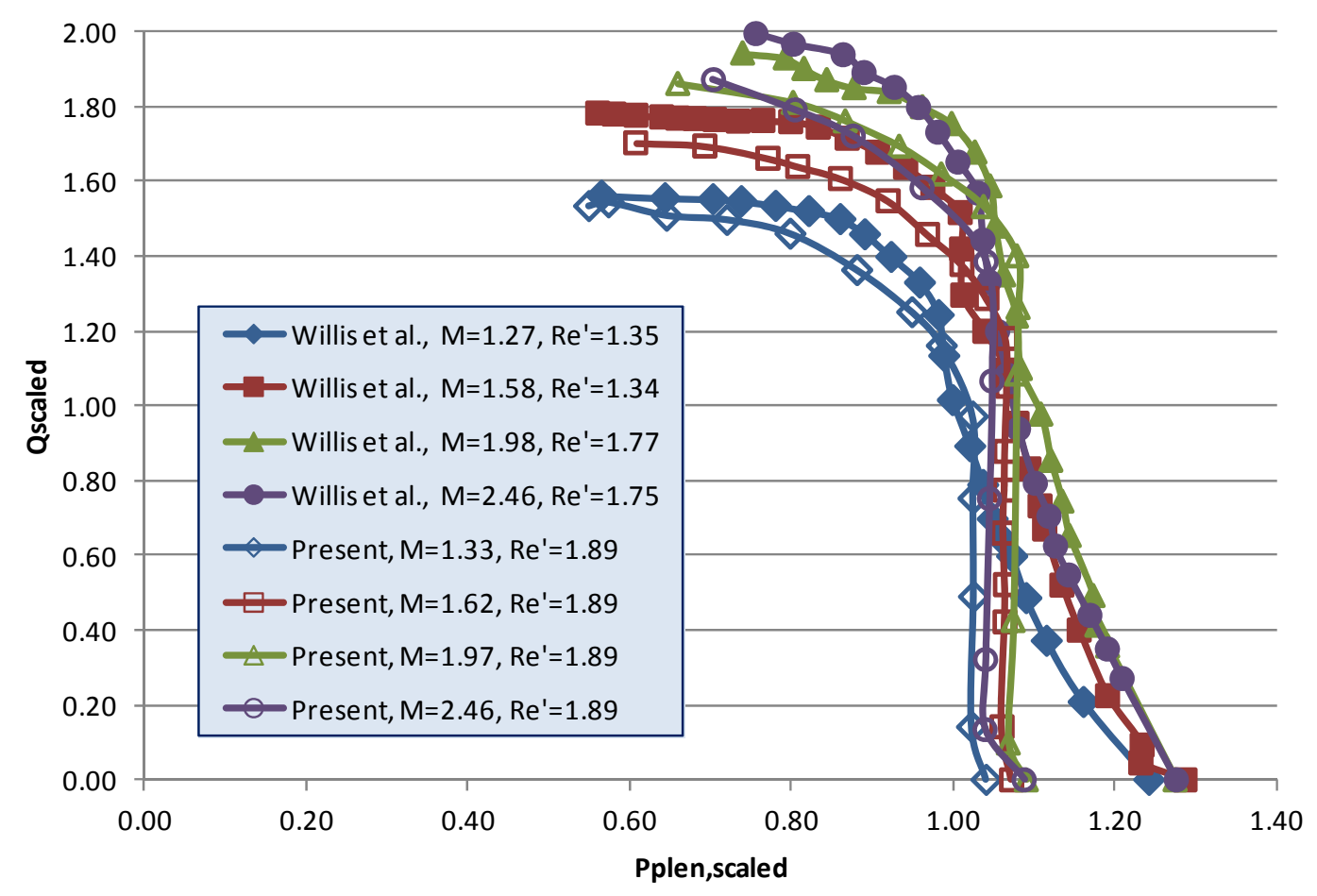

Figure 18.- Single and multi-hole $20^{\circ}$ data scaled per Slater correlation. 


\section{Preliminary Computational Results}

The methods of computational fluid dynamics (CFD) were applied to simulate the bleed through the $\mathrm{C} 01\left(90^{\circ}\right)$ and the $\mathrm{C} 02\left(20^{\circ}\right)$ bleed hole configurations. The flow conditions simulated were those of FC003, which were for a nominal Mach number of 1.4 with Reynolds number at $2.46 \mathrm{E}+07 / \mathrm{m}$. The WindUS code was used to solve the Reynolds-Average Navier-Stokes equations for the steady-state flow using upwind methods and the Menter SST turbulence model. Slater (Ref. 1) discusses the use of Wind-US for simulation of flows through bleed holes.

The computational flow domain modeled portions of the tunnel test section, bleed hole, and plenum. Geometric symmetry about a streamwise vertical plane at the center of the hole allowed the flow domain to be reduced to include only half of the hole, tunnel, and plenum. The modeling also assumed a row of holes perpendicular to the direction of the core tunnel flow. Therefore, a vertical, streamwise symmetry plane was placed equidistant between adjacent holes. Thus, the flow domain only included a streamwise slice of the tunnel and plenum that included only one-half of one bleed hole. The sides of the flow domain were modeled with symmetry boundary conditions. The top of the flow domain was a horizontal plane located at $10.16 \mathrm{~cm}$ (4.0 in.) above the test section bottom wall and modeled with an inviscid wall boundary condition. The inflow boundary was placed upstream of the bleed hole at the reference station at which the boundary layer properties were measured in the experiment. The inflow boundary conditions were specified with a turbulent boundary layer profile obtained from a separate CFD simulation to match the boundary layer edge Mach number and thickness as measured in the experiment. An outflow boundary was placed $3.81 \mathrm{~cm}$ (1.5 in.) downstream of the bleed hole within the tunnel and specified with a supersonic outflow boundary condition. Another outflow boundary was specified at the bottom of the bleed plenum to extract the bleed flow. This boundary was specified with a subsonic outflow boundary condition with the static pressure specified. This outflow boundary condition was used to set the plenum static pressure, which controlled the rate of bleed flow. The surfaces of the tunnel test section floor, bleed hole, and plenum completed the flow domain and adiabatic, viscous wall boundary conditions were applied. The bleed plenum was sized large such that the bleed flow dissipated to near quiescent flow within the bleed plenum and the static pressure specified at the plenum outflow approximately equaled the static pressure in the plenum. The plenum was shaped to form a converging nozzle at the bottom of the plenum where the outflow boundary was placed.

The computational grid for the flow domain was automatically generated and with specification of the bleed hole diameter, bleed hole inclination angle, and hole spacing within the row. Since the experiment only involved one bleed hole, a series of CFD simulations were performed to determine that the hole spacing within the row had to be 4.0 hole diameters to avoid interaction between bleed holes. Structured grids were generated using 13 blocks in which grid lines were contiguous across the block boundaries. The grid resolution normalized by the hole diameter was 0.03378 within the hole. The grids consisted of approximately $2.5 \times 10^{6}$ grid points.

The CFD simulations were performed over a series of plenum pressures. Figure 19 shows the variation of the flow coefficients with comparison to the experimental data and the comparisons are very good. Some differences are apparent for the $20^{\circ}$ hole at plenum pressure ratios about 0.34 . The good agreement boosts confidence in both the experiment and CFD data.

Figure 20 shows Mach number contours of the bleed flow on the hole symmetry plane for the supercritical operating point on the flow coefficient curve, which occurs for the lowest value of bleed plenum pressure. The $90^{\circ}$ hole requires significant turning of the bleed flow, which manifests itself as a detached barrier shock at the top of the hole, a recirculation region at the front of the hole, and a supersonic jet toward the back of the hole. The jet extends into the plenum, but is dissipated. The flow for the $20^{\circ}$ hole does not require a barrier shock; however, a supersonic jet forms that extends into the plenum before dissipating. 


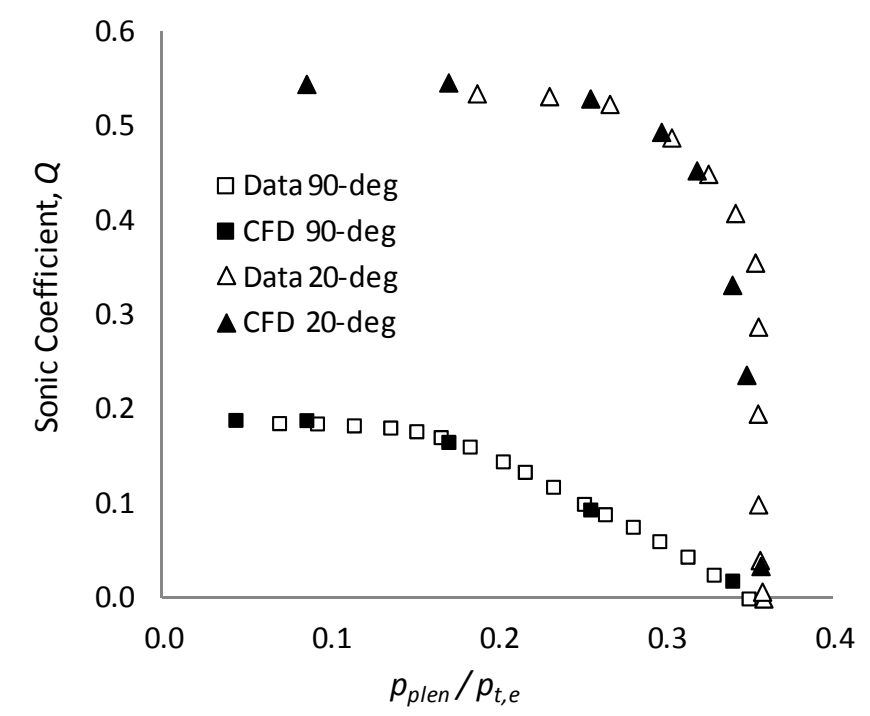

Figure 19.-Comparison of the flow coefficients between CFD and experiment for the $90^{\circ}$ and $20^{\circ}$ bleed holes at $\mathrm{M}_{b l k}=1.4$ and $\mathrm{Re}^{\prime}=2.46$.
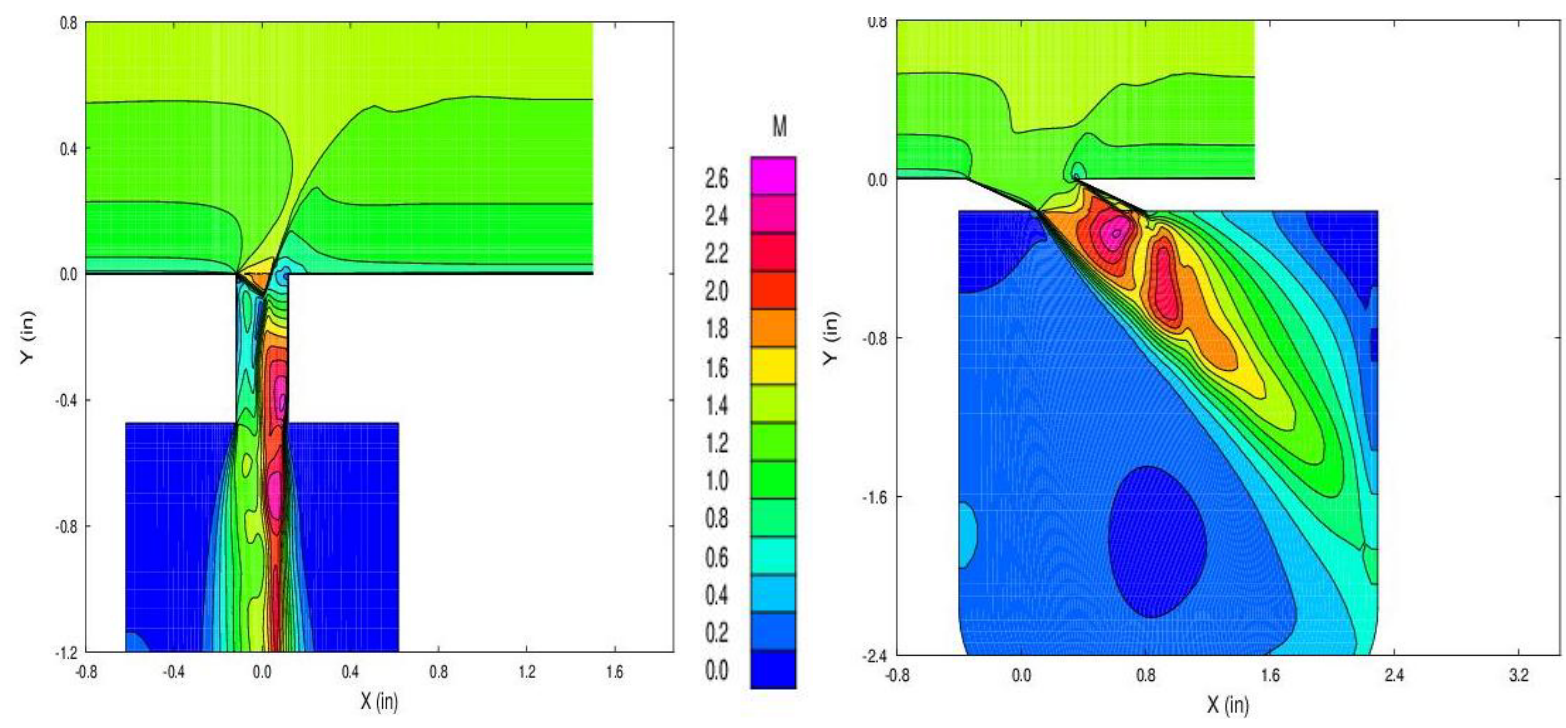

Figure 20.-Mach contours for the super-critical flow through the $90^{\circ}$ (left) and $20^{\circ}$ (right) bleed holes.

\section{Summary and Conclusions}

Flow coefficient data for $90^{\circ}$ and $20^{\circ}$ single bleed holes have been obtained and compared to multihole data under similar conditions. The results show that the $90^{\circ}$ hole data differs most under supercritical operation and the $20^{\circ}$ data differs most under subcritical operation. The preliminary CFD shows good agreement with the experimental results. The single-hole studies will be continued under Phase II of the FIBE project looking initially at intermediate hole inclination angles and length-to-diameter ratios. This will then be followed by boundary layer to hole diameter scaling and also entrance conditions (radius) to the hole. These data will be used to develop improved bleed models that can account for these effects. Finally, Phase III will look at bleed regions with and without shock waves to validate the performance of the resulting bleed models. 


\section{References}

1. Slater, J.W., "Improvements in Modeling $90^{\circ}$ Bleed Holes for Supersonic Inlets," AIAA Paper 2009-0710, 47th AIAA Aerospace Sciences Meeting and Exhibit, Orlando, FL, January 5-8, 2009 (also NASA/TM-2009-215597).

2. Willis, B.P., Davis, D.O., and Hingst, W.R., "Flow Coefficient Behavior for Boundary-Layer Bleed Holes and Slots," AIAA Paper 95-0031, 33rd AIAA Aerospace Sciences Meeting and Exhibit, Reno, NV, January 9-12, 1995 (also NASA TM-106846).

3. Davis, D.O., Grimes, M., and Schoenenberger, M., "Effect of Flow Misalignment and Multi-Hole Interaction on Boundary-Layer Bleed Hole Flow Coefficient Behavior," Proceedings of the ASME Fluids Engineering Division, FED-Vol. 242, American Soc. of Mech. Eng., New York, 1996, pp. 323-328 (also NASA TM-107480).

4. Davis, D.O., "Fundamental Bleed Experiments at NASA Glenn Research Center 1995-1999," 1st Shock Wave/Boundary Layer Interaction Workshop, Cleveland, OH, April 15-16, 2008.

5. Bodner, B.P., Davis, D.O., Hingst, W.R., and Greber, I., "Experimental Investigation of the Effect of a Single Bleed Hole on a Supersonic Turbulent Boundary Layer," AIAA Paper 96-2797, 32nd AIAA Joint Propulsion Conference and Exhibit, Lake Buena Vista, FL, July 1-3, 1996.

6. Bodner, J.P., "Experimental Investigation of the Effect of a Single Bleed Hole on a Turbulent Supersonic Boundary Layer," M.S. Thesis, Dept. of Mechanical and Aerospace Engineering, Case Western Reserve University, Cleveland, OH, May 1996.

7. Schoenenberger, M., Greber, I., and Davis, D. O., "Flow Measurements Downstream of a Single Bleed Hole in a Subsonic, Turbulent Boundary Layer Using a New 5-Hole Pressure Probe," AIAA Paper 99-0293, 37th AIAA Aerospace Sciences Meeting and Exhibit, Reno, NV, January 11-14, 1999.

8. Schoenenberger, M., "Experimental Investigation of a Bleed Hole in a Subsonic Turbulent Boundary Layer," M.S. Thesis, Dept. of Mechanical and Aerospace Engineering, Case Western Reserve University, Cleveland, OH, May 1998.

9. Davis, D.O., and Reichert, B.A., "Ethylene Trace-Gas Techniques for High-Speed Flows," AIAA Paper 94-0733, 32nd AIAA Aerospace Sciences Meeting and Exhibit, Reno, NV, January 10-13, 1994.

10. Davis, D.O., Willis, B.P., Hunter, G.W., Liu, C-C., and Wu, Q., "Mass-flow Measurement Using a Hydrocarbon Trace-Gas Technique," Proceedings of the ASME Fluids Engineering Division, FEDVol. 239, American Soc. of Mech. Eng., New York, 1996, pp. 465-469.

11. van Driest, E.R., "Turbulent Boundary Layer in Compressible Fluids," J. Aeronautical Sciences, Vol. 18, 1951, pp. 145-160. 


\begin{tabular}{|c|c|c|c|c|c|}
\hline \multicolumn{5}{|c|}{ REPORT DOCUMENTATION PAGE } & $\begin{array}{l}\text { Form Approved } \\
\text { OMB No. 0704-0188 }\end{array}$ \\
\hline \multicolumn{6}{|c|}{$\begin{array}{l}\text { The public reporting burden for this collection of information is estimated to average } 1 \text { hour per response, including the time for reviewing instructions, searching existing data sources, gathering and maintaining the } \\
\text { data needed, and completing and reviewing the collection of information. Send comments regarding this burden estimate or any other aspect of this collection of information, including suggestions for reducing this } \\
\text { burden, to Department of Defense, Washington Headquarters Services, Directorate for Information Operations and Reports (0704-0188), } 1215 \text { Jefferson Davis Highway, Suite } 1224 \text {, Allington, VA } 222202-402 \text {. } \\
\text { Respondents should be aware that notwithstanding any other provision of law, no person shall be subject to any penalty for failing to comply with a collection of information if it does not display a currently valid OMB } \\
\text { control number. } \\
\text { PLEASE DO NOT RETURN YOUR FORM TO THE ABOVE ADDRESS. }\end{array}$} \\
\hline \multicolumn{2}{|c|}{$\begin{array}{l}\text { 1. REPORT DATE (DD-MM-YYYY) } \\
01-08-2012\end{array}$} & \multicolumn{3}{|c|}{$\begin{array}{l}\text { 2. REPORT TYPE } \\
\text { Technical Memorandum }\end{array}$} & 3. DATES COVERED (From - To) \\
\hline \multirow{3}{*}{\multicolumn{5}{|c|}{$\begin{array}{l}\text { 4. TITLE AND SUBTITLE } \\
\text { Research on Supersonic Inlet Bleed }\end{array}$}} & 5a. CONTRACT NUMBER \\
\hline & & & & & 5b. GRANT NUMBER \\
\hline & & & & & 5c. PROGRAM ELEMENT NUMBER \\
\hline \multirow{3}{*}{\multicolumn{5}{|c|}{$\begin{array}{l}\text { 6. AUTHOR(S) } \\
\text { Davis, David, O.; Vyas, Manan, A.; Slater, John, W. }\end{array}$}} & 5d. PROJECT NUMBER \\
\hline & & & & & 5e. TASK NUMBER \\
\hline & & & & & $\begin{array}{l}\text { 5f. WORK UNIT NUMBER } \\
\text { WBS 984754.02.07.03.13.02 }\end{array}$ \\
\hline \multicolumn{5}{|c|}{$\begin{array}{l}\text { 7. PERFORMING ORGANIZATION NAME(S) AND ADDRESS(ES) } \\
\text { National Aeronautics and Space Administration } \\
\text { John H. Glenn Research Center at Lewis Field } \\
\text { Cleveland, Ohio 44135-3191 }\end{array}$} & $\begin{array}{l}\text { 8. PERFORMING ORGANIZATION } \\
\text { REPORT NUMBER } \\
\text { E-18208 }\end{array}$ \\
\hline \multirow{2}{*}{\multicolumn{5}{|c|}{$\begin{array}{l}\text { 9. SPONSORING/MONITORING AGENCY NAME(S) AND ADDRESS(ES) } \\
\text { National Aeronautics and Space Administration } \\
\text { Washington, DC 20546-0001 }\end{array}$}} & $\begin{array}{l}\text { 10. SPONSORING/MONITOR'S } \\
\text { ACRONYM(S) } \\
\text { NASA }\end{array}$ \\
\hline & & & & & $\begin{array}{l}\text { 11. SPONSORING/MONITORING } \\
\text { REPORT NUMBER } \\
\text { NASA/TM-2012-217620 }\end{array}$ \\
\hline \multicolumn{6}{|c|}{$\begin{array}{l}\text { 12. DISTRIBUTION/AVAILABILITY STATEMENT } \\
\text { Unclassified-Unlimited } \\
\text { Subject Category: } 02 \\
\text { Available electronically at http://www.sti.nasa.gov } \\
\text { This publication is available from the NASA Center for AeroSpace Information, 443-757-5802 }\end{array}$} \\
\hline \multicolumn{6}{|c|}{ 13. SUPPLEMENTARY NOTES } \\
\hline \multicolumn{6}{|c|}{$\begin{array}{l}\text { 14. ABSTRACT } \\
\text { Phase I data results of the Fundamental Inlet Bleed Experiments project at NASA Glenn Research Center (GRC) are presented which } \\
\text { include flow coefficient results for two single-hole boundary-layer bleed configurations. The bleed configurations tested are round holes at } \\
\text { inclination angles of } 90^{\circ} \text { and } 20^{\circ} \text { both having length-to-diameter ratios of } 2.0 \text {. Results were obtained at freestream Mach numbers of } 1.33 \text {, } \\
1.62,1.98,2.46 \text {, and } 2.92 \text { and unit Reynolds numbers of } 0.984,1.89 \text {, and } 2.46 \times 10^{7} / \mathrm{m} \text {. Approach boundary-layer data are presented for each } \\
\text { flow condition and the flow coefficient results are compared to existing multi-hole data obtained under similar conditions. For the } 90^{\circ} \text { hole, } \\
\text { the single and multi-hole distributions agree fairly well with the exception that under supercritical operation, the multi-hole data chokes at } \\
\text { higher flow coefficient levels. This behavior is also observed for the } 20^{\circ} \text { hole but to a lesser extent. The } 20^{\circ} \text { hole also shows a markedly } \\
\text { different characteristic at subcritical operation. Also presented are preliminary results of a Computational Fluid Dynamics (CFD) analysis of } \\
\text { both configurations at the Mach } 1.33 \text { and a unit Reynolds number of } 2.46 \times 10^{7} / \mathrm{m} \text {. Comparison of the results shows the agreement to be very } \\
\text { good. }\end{array}$} \\
\hline \multicolumn{6}{|c|}{$\begin{array}{l}\text { 15. SUBJECT TERMS } \\
\text { Flow coefficients; Inlet flow; Mach number; Static pressure; Supersonic flow; Supersonic inlets; Bleeding; Boundary layer control; } \\
\text { Boundary layer flow; Boundary layer separation; Compressible flow }\end{array}$} \\
\hline \multicolumn{3}{|c|}{ 16. SECURITY CLASSIFICATION OF: } & $\begin{array}{l}\text { 17. LIMITATION OF } \\
\text { ABSTRACT }\end{array}$ & $\begin{array}{l}\text { 18. NUMBER } \\
\text { OF }\end{array}$ & $\begin{array}{l}\text { 19a. NAME OF RESPONSIBLE PERSON } \\
\text { STI Help Desk (email:help@sti.nasa.gov) }\end{array}$ \\
\hline $\begin{array}{l}\text { a. REPORT } \\
\mathrm{U}\end{array}$ & $\begin{array}{l}\text { b. ABSTRACT } \\
\text { U }\end{array}$ & $\begin{array}{l}\text { c. THIS } \\
\text { PAGE } \\
\text { U }\end{array}$ & UU & $\begin{array}{l}\text { PAGES } \\
30\end{array}$ & $\begin{array}{l}\text { 19b. TELEPHONE NUMBER (include area code) } \\
443-757-5802\end{array}$ \\
\hline
\end{tabular}


